\title{
LA ACTIVIDAD CARBONÍFERA EN COLOMBIA: UN ANÁLISIS A PARTIR DE LOS INSTRUMENTOS DE ORDENAMIENTO TERRITORIAL Y PLANIFICACIÓN SOCIOECONÓMICA*
}

\author{
Johann Dilak Julio Estrada** \\ Sandra Milena Bulla Ortega*** \\ Julio CÉsar Rojo Ospina ${ }^{* * * *}$
}

\section{Resumen}

El presente artículo analiza el estado de la producción minera de carbón en Colombia a partir de la vocación presente en los municipios donde dicha actividad se desarrolla. En la última década, el desarrollo de la actividad minera en Colombia ha tenido un incremento

\footnotetext{
Este artículo tiene como punto de partida los avances presentados en la tesis de maestría titulada: "Análisis del impacto de la actividad minera de carbón en los municipios productores en Colombia, teniendo en cuenta los indicadores de desarrollo social incluidos en el plan de ordenamiento territorial y el plan de desarrollo municipal", presentada en el marco de la Maestría en Responsabilidad Social y Sostenibilidad de la Facultad de Finanzas, Gobierno y Relaciones Internacionales de la Universidad Externado de Colombia.

** msc en Gestión urbana. Profesor titular, Universidad Externado de Colombia; docente-investigador adscrito al Centro de Investigaciones y Proyectos Especiales (CIPE), Facultad de Finanzas, Gobierno y Relaciones Internacionales, Universidad Externado de Colombia, Bogotá (Colombia). [johann.julio@uexternado.edu.co]; [https:// orcid.org/0000-0001-6984-1893].

*** MSc en Responsabilidad Social y Sostenibilidad. Docente de cátedra, Universidad del Área Andina, Bogotá (Colombia), y profesional especializado del Ministerio de Minas y Energía, Dirección de Formalización Minera, Bogotá (Colombia). [ingesamibuor@gmail.com]; [https://orcid.org/0000-0001-5155-3551].

${ }^{* * * *}$ MSc en Responsabilidad Social y Sostenibilidad. Profesional especializado del Ministerio de Minas y Energía, Dirección de Formalización Minera, y consultor en asuntos mineros y ambientales, Bogotá (Colombia). [juliorojo1@hotmail.com]; [https://orcid.org/0000-0001-7738-7969].
}

Recibido: 26 de junio de 2019 / Modificado: 11 de septiembre de 2019 / Aceptado: 16 de septiembre de 2019

Para citar este artículo

Julio, J. D., Bulla, S. M. y Rojo, J. C. (2020). La actividad carbonífera en Colombia: un análisis a partir de los instrumentos de ordenamiento territorial y planificación socioeconómica. OPERA, 26, 77-118.

DOI: https://doi.org/10.18601/16578651.n26.06 
positivo, destacándose como el quinto mayor productor y exportador de carbón en el mundo; sin embargo, este desarrollo no guarda una estrecha relación con los indicadores sociales de los municipios que soportan la actividad. La investigación intenta establecer cómo el reconocimiento de la actividad minera por parte de los instrumentos de desarrollo socioeconómico y de planeación territorial es una variable que puede explicar este fenómeno. El abordaje metodológico consistió en establecer relaciones entre el volumen de la producción y la presencia o no de directrices dentro de los instrumentos de planeación que permitiesen observar el reconocimiento de la vocación minera dentro de los territorios y cómo esta podría apuntar a facilitar el desarrollo de la actividad. Para adelantar dicho propósito se construyó una tipología basada en las características de la producción en la que se sistematizó y analizó la información en cuatro categorías. El análisis permitió identificar resultados no paramétricos sobre la vocación de los territorios y el reconocimiento de la actividad minera como pilar de la actividad económica del municipio, la cual se puede explicar a partir del grado de importancia y mención que dicha actividad registra en la agenda de planeación municipal.

Palabras clave: sostenibilidad; minería; carbón; indicadores sociales; planes de ordenamiento territorial; planes de desarrollo municipal.

COAL MINING ACTIVITY IN COLOMBIA: AN ANALYSIS FROM INSTRUMENTS OF SOCIOECONOMIC DEVELOPMENT AND TERRITORIAL PLANNING

\section{Abstract}

This article analyzes the state of coal mining production in Colombia based on the vocation present in the municipalities where this activity takes place. In the last decade the development of mining activity in Colombia has had a positive increase, standing out as the fifth largest producer and exporter of coal in the world; However, this development is not closely related to the social welfare indicators of the municipalities that support the activity.

The research tries to establish how the recognition of mining activity by the instruments of socioeconomic development and territorial planning is a variable that can explain this phenomenon. The methodological approach consisted in establishing relations between the volume of production and the presence or absence of guidelines within the planning instruments that allowed observing the recognition of the mining vocation within the territories and how this could aim to facilitate the development of coal mining.

To advance this purpose, a typology was built based on the characteristics of production in which the information was systematized and analyzed in four categories. The analysis allowed to identify non-parametric results on the vocation of the territories and the recognition of mining activity as a pillar of the economic activity of the municipality, which can be explained from the degree of importance and mention that said activity records in the agenda of the local planning instruments.

Key words: Mining; coal; royalties; social indicators; sustainability. 


\section{MINERÍA DE CARBÓN EN COLOMBIA}

En la actualidad, Colombia es el quinto exportador mundial de carbón con un 5,4\% del volumen total de las exportaciones; a su vez, es el país con mayores reservas de carbón en América Latina (вр, 2019), esto se traduce en que a 2016, Colombia contaba con reservas probadas de 4881 millones de toneladas (Mt) de carbón antracítico y bituminoso, las mayores en Latinoamérica (48,3\%), las cuales corresponden aproximadamente al $0,6 \%$ de las reservas mundiales (ANM, 2018). Con la tasa de explotación actual, las reservas medidas de carbón en Colombia aseguran más de 120 años de producción, suficientes para participar a gran escala en el mercado internacional y abastecer la demanda interna (UPME, 2005, p. 7). En el 2017 el carbón representó el 67,50\% (us\$ 3235,1 millones) del producto interno minero (PIB); $1,36 \%$ del PIB nacional y el $87,7 \%$ del total de regalías mineras recaudadas. Las exportaciones a 2018 representaron el 19,5\% del valor de las exportaciones del país (ANM,
2018), lo que ubica al carbón como el mineral más importante de la economía nacional.

Por otra parte, la British Petroleum (BP), en su informe de indicadores de minería, reportó que la producción de carbón en el país creció en promedio cerca del 2,6\% anual entre los años 2007 y 2017, debido al crecimiento de la producción de los proyectos mineros de La Guajira y Cesar, consolidándose como el mineral más importante del sector minero colombiano, pasando de 50,5 Mt producidas en 2008 a 62,2 Mt en 2017 (вр, 2019).

De igual manera, es posible determinar que la industria del carbón en el país está dominada por grandes productores con sus propios puertos y ferrocarriles como son: Glencore, Drummond y Cerrejón, que es propiedad en partes iguales de BHP Billiton, Anglo American Plc y Xstrata Plc (upme, 2014, p. 34). La figura 1 presenta la tendencia de crecimiento del sector minero desde 2011 a 2016.

La actividad minera en el país ha estado amparada en un marco jurídico que ha clasificado la producción del mineral, así como

FIGURA 1. PRODUCCIÓN DE CARBÓN POR AÑO, 2011-2016

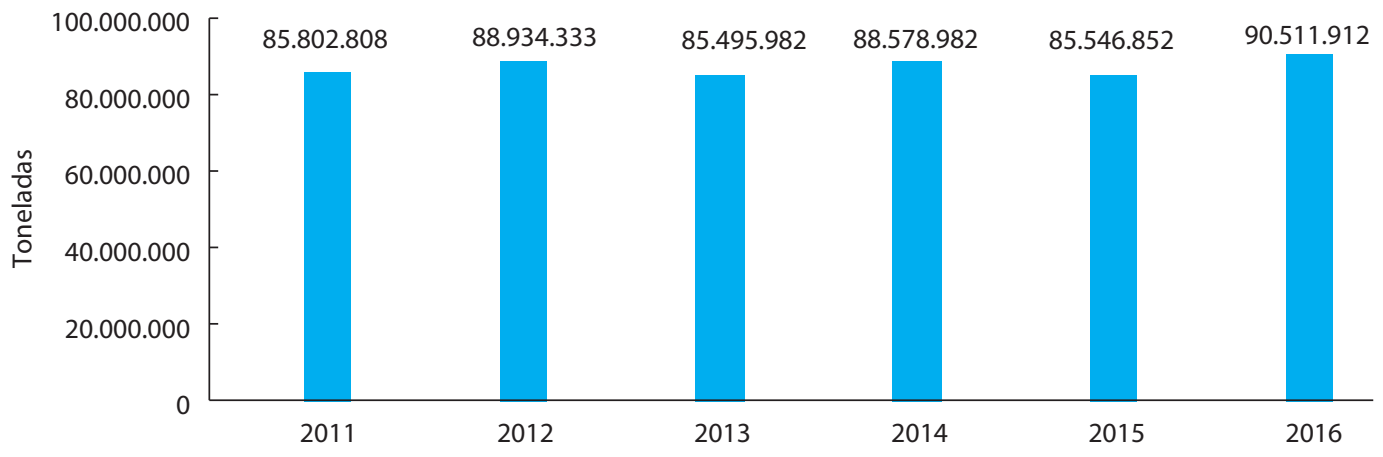

Fuente: UPME (2017). 
también las diferentes modalidades para el aprovechamiento del recurso. Uno de los marcos normativos para el sector de la minería lo constituye la Ley 20 de 1969, por medio de la cual se dictaron disposiciones en materia de minas e hidrocarburos, dicha ley fue reglamentada mediante el Decreto 1275 de 1970, en el cual se establecieron figuras legales que han permitido el desarrollo de actividades de exploración y explotación de minerales, entre ellas la licencia de exploración, permisos, concesiones, contratos en virtud de aporte y el reconocimiento de cédulas reales, denominadas Registros de Propiedad Privada. Mediante el Decreto 2477 de 1986 se modificó la norma reglamentaria de la Ley Minera, que ratificó la figura de contrato en virtud de aporte y los contratos de concesión, entre otros, así como la declaratoria de la industria minera como de utilidad pública y de interés social nacional.

A finales de la década de los ochenta, el Gobierno nacional impulsó una nueva reforma a la Ley Minera, la cual se materializó con la expedición del Código de Minas, Decreto-Ley 2655 de 1988, donde se incluyeron algunos aspectos esenciales para el desarrollo de la actividad, como lo fue la vinculación de la mano de obra local en los proyectos mineros y la clasificación de la minería de acuerdo con el tamańo del emprendimiento, volumen de explotación y modalidad (a cielo abierto o subterránea). En este sentido, si al finalizar la licencia de exploración el resultado era un proyecto de mediana o gran minería, se otorgaba un contrato de concesión, pero si era de pequeña minería, se otorgaba una licencia de explotación.
Lo anterior fue determinante para el desarrollo de las distintas modalidades de minería en el país, toda vez que pretendió reconocer el estado de la actividad a ese momento y otorgar un marco para la actividad, consecuente con el emergente proceso de descentralización del país. En el año 2001, la actividad experimentó una nueva transición legislativa materializada con la expedición de la Ley 685 de 2001. Esta ley estableció una única modalidad de otorgamiento del contrato de concesión, el cual tiene un periodo de treinta años, en los cuales se incluye la etapa de exploración, construcción y montaje y, por último, la explotación, además introduce la posibilidad de prórroga, beneficio que no estaba contemplado en el anterior régimen. Lo anterior deja entrever la intención por parte del Gobierno nacional acerca de la vocación de permanencia de la actividad en la dinámica económica nacional.

Por otra parte, la Constitución Política de 1991, en su artículo 332, estableció la contraprestación económica a título de regalía por el aprovechamiento de los recursos naturales no renovables, estableciendo la creación del Sistema General de Regalías. En el artículo 360 definió que parte de los ingresos derivados de la actividad debían destinarse a los territorios donde la actividad tuviera lugar, y en el artículo 361 estableció que los recursos por concepto de regalías deberían dirigirse al financiamiento de proyectos regionales de inversión definidos como prioritarios en los planes de desarrollo de las respectivas entidades territoriales. Dicha prerrogativa ha estado presente en la distribución de los recursos a lo largo del tiempo y ha sido objeto de consideración en cada una de las normas que han versado sobre la materia, tanto 
en la leyes 141 de 1994 y 756 de 2002, como en la reforma constitucional de los artículos 360 y 361 realizada a partir del Acto Legislativo 005 de 2011, reglamentado por la Ley 1530 de 2012. Se estableció así que los ingresos del Sistema General de Regalías se destinarían al financiamiento de proyectos para el desarrollo social, económico y ambiental de las entidades territoriales buscando mejorar las condiciones sociales de la población (PNUD, 2015).

\section{INSTRUMENTOS DE PLANIFICACIÓN EN COLOMBIA}

La planeación socioeconómica como principio rector del rumbo de la sociedad tiene una larga tradición en el país. A partir de la Constitución de 1991, este principio derivó en la promulgación de la Ley 152 de 1994, en la cual cada gobierno nacional, departamental o local, al inicio de su periodo, debe presentar ante el órgano legislativo que corresponda la hoja de ruta por los cuatro años de su mandato (Economía Colombiana, 2015).

Estos planes de desarrollo deberán guiarse, entre otros, por la prioridad del gasto público social en las inversiones públicas, la coherencia en el desarrollo de programas y proyectos conforme a los objetivos de desarrollo y la sustentabilidad ambiental. En definitiva, es posible afirmar que este ejercicio de planeación del desarrollo da cuenta de la comprensión de los mandatarios locales de la vocación del territorio y establece las prioridades de inversión del municipio en materia socioeconómica en virtud de la descentralización política y administrativa.
Por tal motivo, los planes de desarrollo de las entidades territoriales integran una parte estratégica y un plan de inversiones a mediano y corto plazo, donde las entidades territoriales desarrollan su autonomía en materia de planeación del desarrollo económico, social y de la gestión ambiental, en el marco de las competencias, los recursos y las responsabilidades que les ha atribuido la Constitución y la mencionada ley.

De esta manera, los planes de desarrollo municipales son el instrumento idóneo para desarrollar la vocación de las entidades territoriales a la luz de los Planes de Ordenamiento Territorial (РОт). Esta figura de ordenamiento mencionada en la Constitución y desarrollada a través de la Ley 388 de 1997, busca brindar al municipio instrumentos para regular la utilización, transformación y ocupación del espacio, de acuerdo con las estrategias de desarrollo socioeconómico y en armonía con el medio ambiente y las tradiciones históricas y culturales de los territorios (Ley 388 de 1997). Esta figura establece un horizonte de planeación a largo plazo, el cual debe desarrollarse de manera armónica a partir de lo consignado en los planes de desarrollo.

Por tal razón, se estipula que en los POT deben quedar consignados los objetivos, las directrices, las políticas, las estrategias, las metas, los programas, las actuaciones y las normas relativas a orientar y administrar el desarrollo físico del territorio y la utilización del suelo. Según el número de habitantes, la ley estableció tres categorías de instrumentos: Esquemas de Ordenamiento Territorial (вот) para los municipios con población inferior a 30.000 habitantes; Planes Básicos de Ordenamiento 
territorial (РвОт) para los municipios con población entre 30.000 y 100.000 habitantes, y Planes de Ordenamiento Territorial (рот) para los municipios con población superior a 100.000 habitantes. Igualmente, la ley estableció una vigencia de tres periodos constitucionales (12 años) para estos instrumentos, la cual, una vez superada, se sugiere que debería suscitar la formulación de nuevos РОт, Рвот o EOT.

Durante los últimos veinte años, el desarrollo de estos dos instrumentos a nivel municipal ha permitido resaltar el carácter de la planeación socioeconómica y territorial como actividades dinámicas y estratégicas enfocadas en dotar a las entidades territoriales de herramientas para el ejercicio de su autonomía y el reconocimiento de su vocación económica, social y ambiental, por lo que un análisis de estos instrumentos permitiría observar cómo la vocación del territorio debería guardar sintonía con lo consignado en dichos planes.

Sin óbice para lo anterior, se hace importante aclarar que dicha autonomía municipal ha sido cuestionada a partir de un desarrollo normativo que da cuenta de la tensión jurídica existente entre el desarrollo de actividades de tipo minero en los municipios y la potestad de estos para reconocer la presencia de la actividad.

La tensión radica en que si bien el ordenamiento territorial se funda en la autonomía del municipio para la administración de su suelo y en la escogencia de su visión de desarrollo, acciones que se pueden ubicar dentro de los procesos democráticos como bottomup, la exploración y explotación fruto del ordenamiento minero obedece a decisiones de tipo top-down que provienen de la nación y se encuentran presentes en la Ley 685 de 2001, actual Código Minero; en el Decreto 2201 de 2003 y 934 de 2013, que establecen, en su orden, que los instrumentos de ordenamiento municipal no podrán ser oponibles a la ejecución de proyectos, obras o actividades de utilidad pública e interés social promovidas por la nación, y que la decisión de establecer exclusiones o restricciones a la actividad es en todo caso competencia de la autoridad minera y ambiental.

Por tanto, la tensión es clara, la visión del desarrollo de las comunidades proveniente de un ejercicio democrático puede verse afectada por disposiciones de autoridades centralizadas que no necesariamente tienen un vínculo territorial (Zapata, 2013; Julio y Herrera, 2016). Lo cual podría verse reflejado en algunas de las condiciones que presentan los territorios expuestos a la actividad, en los cuales la desarticulación de estos ordenamientos permite observar anomalías en indicadores sociales de índole municipal (Zapata, 2013).

\section{IMPORTANCIA DE LOS INDICADORES SOCIALES COMO RESULTADO DE LA ACTIVIDAD MINERA Y SU IMPACTO EN EL DESARROLLO DE LA ACTIVIDAD A NIVEL NACIONAL}

El concepto tradicional de desarrollo sostenible (Informe Brundtland o Nuestro Futuro Común, 1987) ha sido ampliamente debatido para aplicarlo al sector minero, teniendo como primicia que los recursos explotados son finitos (Gudynas, 2000). Esto ha generado el 
surgimiento de nuevas aristas en la discusión sobre minería y desarrollo (Leal, 2006; Hernández, 2018), las cuales centran su atención sobre la ponderación y el seguimiento de indicadores sociales e institucionales complementarios a los que simplemente se enfocan en el seguimiento de la producción y crecimiento económico (Campbell, 2009; Kommadath y Rath, 2012). Específicamente, el estudio de la relación entre desarrollo minero y reducción de la pobreza ha centrado la atención de expertos, el estudio a profundidad de casos en África (Campbell, 2009, p. 25) y América Latina (van Teijlingen, 2016) así lo demuestra; sin embargo, para estos autores, el impacto de la actividad en la disminución de la pobreza en las comunidades cercanas a los emprendimientos mineros suele ser bajo (Frederiksen, 2019).

Por otra parte, algunos autores establecen la importancia de la capacidad institucional de los municipios o territorios, así como la existencia y el uso de los instrumentos con que cuentan como factores determinantes para la obtención de resultados positivos a nivel social derivados del desarrollo de la actividad extractiva (Acemoglou y Robinson, 2012; MMSD, 2012), debido a que la desconexión entre los instrumentos de planeación del desarrollo local y nacional con el desarrollo de la actividad minera promueven la aparición de indicadores sociales negativos en el territorio (McEwan, Mawdsley, Banks y Scheyvens 2017; Mancini y Sala, 2018). Mancini y Sala aportan evidencia de 50 estudios a nivel global, en los cuales se estudiaron las consecuencias sociales derivadas de las actividades de extracción minera, en las cuales destacan la presencia de impactos negativos asociados a necesidades básicas insatisfechas o el aumento demográfico en los territorios, así como también impactos asociados a condiciones de salud derivados de la operación y el ambiente por la competencia por el recurso hídrico.

Por tal motivo, para el objetivo de este artículo es importante observar si existe sintonía entre los instrumentos de planeación y la presencia de la actividad en el territorio, explicado a la luz del grado de desarrollo de la actividad minera en términos de volumen de explotación y el comportamiento de ciertos indicadores sociales, institucionales y relativos a las regalías que podrían reflejar la relación entre la actividad minera y la vocación del territorio. Por lo anterior, es pertinente revisar indicadores que nos permitan observar la sostenibilidad de la producción y su articulación con los instrumentos de planeación que el Estado ha desarrollado para acompasar la dinámica económica, social y territorial en los municipios donde la minería tiene lugar.

La identificación de las vocaciones de los municipios objeto de estudio fue realizada a través de la revisión de las herramientas de planeación territorial, con el fin de revisar lo manifestado en relación con la reglamentación de los usos del suelo y la identificación de la actividad minera de carbón entre los mismos.

Asimismo, los planes de desarrollo de los municipios objeto de estudio se revisaron teniendo en cuenta los resultados de los últimos tres periodos de gobierno, con el fin de identificar el contenido estructural, el cual hace referencia al proceso de cómo se planificó el desarrollo social y económico de los municipios durante estos, y si en dicha planificación a la actividad minera se le otorgó algún grado 
de importancia dentro del desarrollo socioeconómico.

En el análisis se contempló la planificación y las decisiones asumidas en cada momento por cada alcalde electo, con el fin de identificar la importancia y el reconocimiento de la actividad extractiva tanto en el discurso como en los proyectos de desarrollo municipal. Para tal fin fue necesario construir una matriz que relacionara a nivel municipal las variables mencionadas. Primero, se verificó la existencia, dentro de los programas que adelantaban los planes de desarrollo municipal, de la vocación tradicional de los municipios y el desempeño de la actividad extractiva. Segunda, se observó si los municipios de estudio incluyeron dentro de sus herramientas de planificación la actividad minera de carbón dentro de los usos del suelo presentes en el territorio. Tercero, se buscó identificar la destinación dada por los municipios productores a los recursos de inversión directa provenientes de las regalías y constatar si esta se encontraba encaminada al desarrollo de proyectos que tuvieran por objetivo mejorar la competitividad de la economía de los municipios y el mejoramiento de las condiciones sociales de la población; por último, se observó si existía algún tipo de interrelación entre los resultados de los indicadores sociales más importantes y el desarrollo de la actividad minera de carbón.

Por último, se verificaron las condiciones en términos de necesidades básicas insatisfechas en los casos de estudio, así como también los registros sobre potenciales beneficiarios de programas sociales en el territorio a partir de los registros validados en el Sisben. Este índice se toma como un indicador de estándar de vida que mediante tres dimensiones busca evaluar variables relativas a la salud, la educación, la vivienda y la vulnerabilidad de los hogares, el cual permite conocer y evaluar en una determinada forma las condiciones de pobreza y vulnerabilidad de dichos hogares (Conpes 117, 2008).

La figura 2 muestra una síntesis de dicho proceso y cómo a partir de la sistematización de la información fue posible desarrollar una tipología para 104 municipios y su posterior análisis.

La muestra para el análisis de los datos corresponde a todos los municipios productores de carbón en Colombia, para ello la fuente de información utilizada fue la Unidad de Planeación Minero Energética (UPME). Esta información se encuentra en el módulo Sistema de Información del Sector Minero Colombiano (Simco), en información municipal y producción nacional de carbón en todas las escalas (gran, minería y pequeña minería).

De acuerdo con lo anterior, se revisó la información de los municipios productores de carbón entre los años 2011 y 2016 en el Simco, dicha búsqueda arrojó un total de 130 municipios productores de carbón; sin embargo, para los propósitos de este estudio fue necesario ajustar la selección a un total de 104 municipios teniendo en cuenta la intermitencia y la muy baja producción de 26 municipios dentro del simco ${ }^{1}$.

\footnotetext{
1 A partir de la producción fue necesario excluir del análisis varias categorías de municipios: Sin producción los últimos seis años. Descartados 13: Briceño, Buenavista, Jenesano, Rondón, Tibasosa (Boyacá); Nilo, Tabio, Ubalá,
} 


\section{FIGURA 2. VARIABLES CONTENIDAS EN EL MARCO METODOLÓGICO PARA LOS CASOS DE ESTUDIO}

VARIABLES (agrupadas en tres matrices):

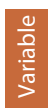

\section{Desarrollo de la actividad} minera de carbón
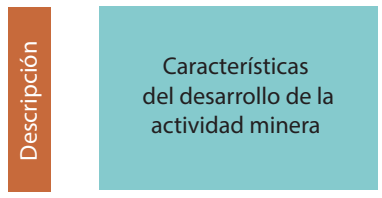

1. Producción anual de carbón

2. Escala de minería

3. Tipo de minería

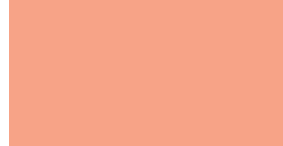

- Estudio correlacional.

- Información cuantitativa y cualitativa, el origen de dicha información está basado en información secundaria.
Indicadores de desarrollo social

Instrumentos relacionados para la planeación de los municipios

Ordenamiento territorial (EOT, POT, PBOPT)

2. Planes de desarrollo municipal

3. Coherencia entre instrumentos

incluyendo la actividad minera
Los indicadores sociales refieren a estudios realizados que midan el estado de la población, sus condiciones de vida y medición de necesidades

\section{Población Sisben}

2. Población total

proyectada

3. $\mathrm{NBI}$

4. Categoría del municipio

\section{Regalías}

Recursos destinados para proyectos a partir del desarrollo de una actividad generadora

1. Ingresos municipales

2. Ingresos de regalías por proyectados por el Ministerio de Hacienda.

3. Desempeño fiscal de los municipios: dependencia de regalías.

4. Líneas de inversión de regalías

Fuente: elaboración propia.

Los 104 municipios seleccionados fueron agrupados de acuerdo con dos criterios, el primero asociado al volumen de producción y el segundo relativo a su ubicación geográfica. Esto permitió inscribir a los territorios en cuatro grandes grupos, arrojando una clasificación particular para el análisis de las variables en cuestión, teniendo como referencia las características particulares de cada categoría, como son: los de la zona norte como los mayores productores de carbón en el país; la zona centro que concentra los municipios con tradición y con mayor número de municipios productores; la zona oriental con municipios de tradición minera, en la cual la producción se encuentra concentrada en cinco municipios; y la última categoría los municipios donde la producción se destaca por ser baja pero constante; los casos se distribuyeron como indica la tabla 1 .

Venecia (Cundinamarca); Cajibio, Patía (Cauca); Herrán (Norte de Santander); Monte Líbano (Córdoba). Municipios que su producción no supere 150 toneladas promedio en los seis años de estudio. Descartados 6: Cómbita, Floresta, Nobsa (Boyacá); Quipile y Tocaima (Cundinamarca); Guavatá (Santander). Municipios sin título minero o con título compartido con otro municipio ya incluido en el estudio. Descartados 7: Aquitania, El Espino, Guacamayas, Nuevo Colón, Saboyá (Boyacá); San Cayetano (Cundinamarca); Toledo (Antioquia). 
TABLA 1. CASOS DE ESTUDIO

\begin{tabular}{|c|l|c|}
\hline Casos & \multicolumn{1}{|c|}{ Departamentos } & Total municipios \\
\hline 1 & $\begin{array}{l}\text { Cesar y La Guajira (Zona } \\
\text { Norte) }\end{array}$ & 8 \\
\hline 2 & $\begin{array}{l}\text { Boyacá y Cundinamarca } \\
\text { (Zona Centro) }\end{array}$ & 55 \\
\hline 3 & $\begin{array}{l}\text { Norte de Santandery } \\
\text { Santander (Zona Orien- } \\
\text { tal 2) }\end{array}$ \\
\hline 4 & $\begin{array}{l}\text { Antioquia, Casanare, } \\
\text { Cauca, Córdoba, Valle } \\
\text { del Cauca (otros muni- } \\
\text { cipios) }\end{array}$ \\
\hline
\end{tabular}

Fuente: elaboración propia.

\section{ANÁLISIS COMPARATIVO ENTRE LOS CASOS DE ESTUDIO}

El análisis de los casos se presenta agrupado en cuatro aspectos: en primer lugar, se hace una descripción de la producción de carbón entre 2011-2016, y cómo ha evolucionado dicha actividad en este periodo; en segundo lugar, se expone información que permita ver el desarrollo de la planeación territorial. Estos datos permitirán observar la relación entre las herramientas de planeación y el grado de desarrollo de la actividad minera; en tercer lugar, se presenta el resultado encontrado frente a la gestión de regalías que los municipios han tenido entre 2011 y 2016 y, finalmente, los resultados de los indicadores sociales. Esto permitirá alinear las conclusiones sobre minería, desarrollo y regalías.

En términos generales, la actividad minera de carbón en Colombia se comporta de manera intermitente en el periodo estudiado; sin embargo, esta siempre estuvo por encima de los 85 millones de toneladas (como se observa en la figura 3).

Igualmente, es posible observar, agregados en el primer caso, la producción de los municipios de La Guajira y Cesar; en el segundo, la producción de Boyacá y Cundinamarca; en el tercero, Santander y Norte de Santander y, el cuarto, los otros departamentos (Antioquia, Cauca, Casanare, Córdoba y Valle del Cauca) (figura 4).

FIGURA 3. PRODUCCIÓN EN MILLONES DE TONELADAS - COLOMBIA, 2011-2016

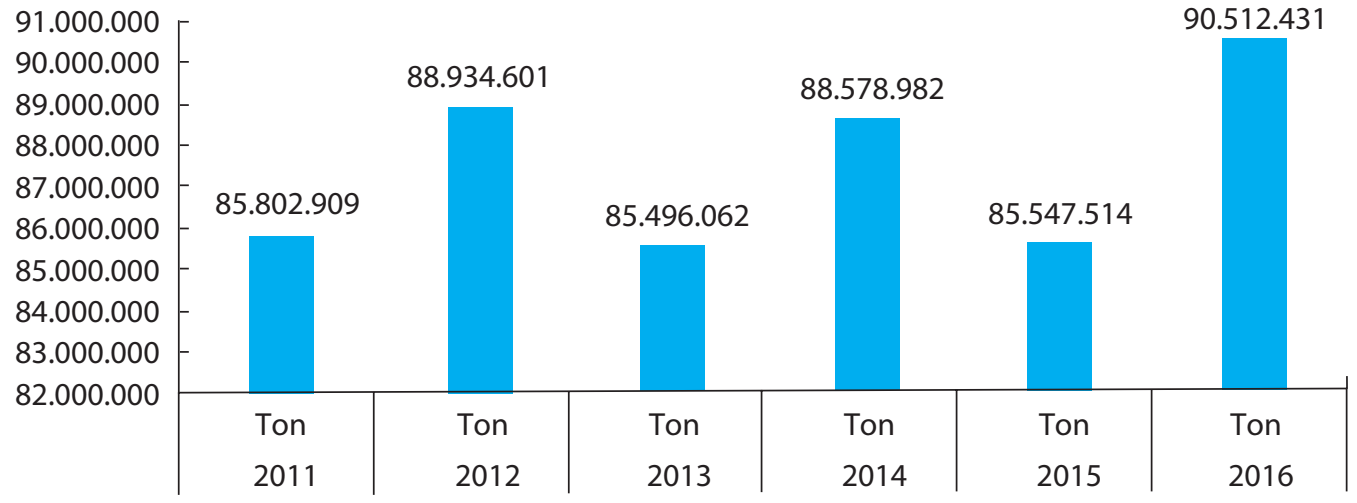

Fuente: elaboración propia. 
FIGURA 4. PORCENTAJE DE PRODUCCIÓN Y NÚMERO DE MUNICIPIOS POR CASO DE ESTUDIO

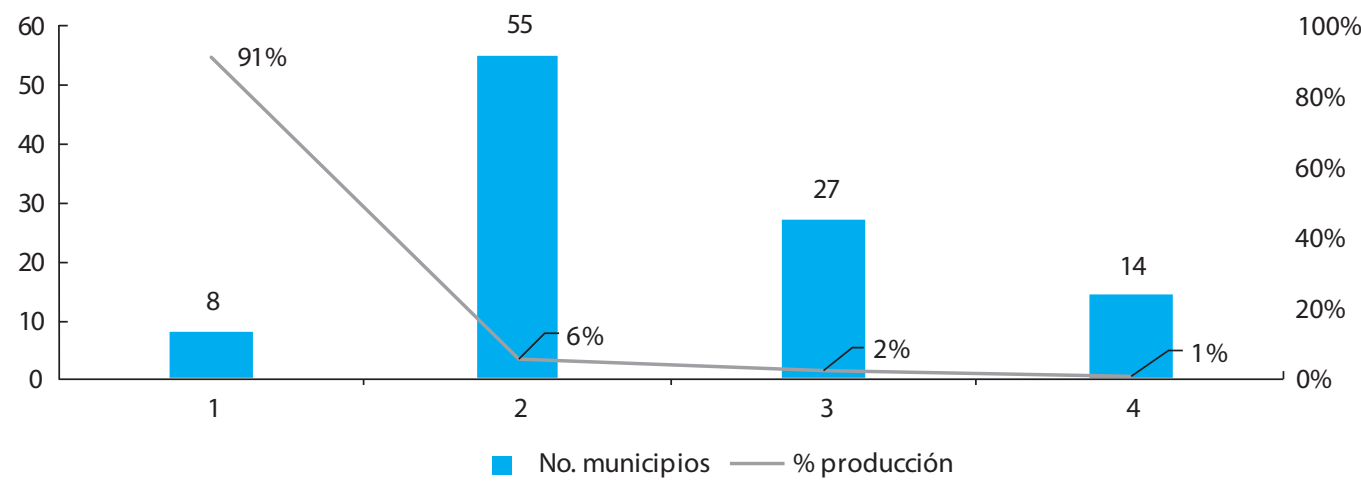

Fuente: elaboración propia.

El caso 1 está compuesto por ocho municipios, cinco pertenecientes al departamento del Cesar: La Jagua de Ibirico, Becerril, Chiriguaná, Agustín Codazzi y El Paso, y tres de La Guajira: Albania, Barrancas y Hato Nuevo. La zona norte representa el $91 \%$ de la producción del país con un promedio de 79.807.625 toneladas anuales, cuyo rango de minería corresponde a gran minería de acuerdo con los rangos establecidos en el Decreto 1666 de 2016. En el caso 2, Boyacá se destaca por ser el departamento con el mayor número de municipios productores, existen 38 municipios que realizan la actividad extractiva de carbón.

En el otro departamento de esta categoría, Cundinamarca, se identificaron 17 municipios, que ocupan el tercer lugar de los departamentos de este estudio, con mayor número de municipios ejerciendo la actividad extractiva. La zona central ha tenido en el periodo evaluado una producción constante, por el orden de 4,8 millones de toneladas promedio en los años 2011-2016, que representan el 6\% del total de la actividad.
El caso 3 lo integran los departamentos de Norte de Santander con veinte municipios con producción de mineral de carbón, y Santander, con un total de siete municipios, con un promedio de 2.176.065 toneladas anuales producidas (Norte de Santander es el departamento con mayor aporte a la producción con un promedio de 2.034.979 Ton/año; y Santander, con de 141.116,37 Ton/año ). Por último, el caso 4 cuenta con catorce municipios productores ubicados en los departamentos de Antioquia, Casanare, Cauca, Córdoba y Valle del Cauca, que agregan un promedio de producción de 612.523 Ton/año, tanto a cielo abierto como de forma subterránea.

Lo anterior arroja una primera conclusión acerca de la minería de carbón en nuestro país, la cual por volumen de producción se concentra en el norte del país y se desarrolla a cielo abierto, específicamente en dos municipios, pero genera una presencia sostenida como vocación económica en otros 102 municipios, especialmente en departamentos como Boyacá, Norte de Santander y Cundinamarca, en 
los cuales la producción se realiza de manera subterránea.

La revisión de los instrumentos de ordenamiento territorial permitió establecer que la minería de carbón se lleva a cabo en municipios con EOT como herramienta de ordenamiento (figura 5), esta es la herramienta propuesta para municipios con poblaciones inferiores a los 30.000 habitantes, propios de territorios en proceso de consolidación y en los cuales se han podido observar conflictos en la determinación de los usos y la vocación del suelo (Ideade, 2015), cambios en las dinámicas poblacionales en las cabeceras municipales y los centros poblados rurales (Ramírez, Castro, Restrepo, Barbosa, 2015) y, sobre todo, un aumento en la extensión del área ocupada (Contreras, 2017).
Al revisar los instrumentos de planeación territorial se encuentra que en el caso 1 , de los ocho municipios, cinco cuentan con EOT y tres con рвот, en estos рот se encontró que todos, excepto el municipio Agustín Codazzi, contemplan la actividad minera en el uso del suelo y como parte de la vocación económica descrita en el componente general de dicho instrumento, es decir, se identifican como un municipio minero.

En cuanto a la vigencia de los instrumentos de ordenamiento territorial, se constató que seis de ellos han superado su vigencia sin que a la fecha se haya publicado la revisión y actualización de los mismos, solo los municipios de La Jagua de Ibirico y Albania (municipios con la mayor producción del país), en los de-

FIGURA 5. FIGURAS DE ORDENAMIENTO TERRITORIAL DE LOS CASOS DE ESTUDIO

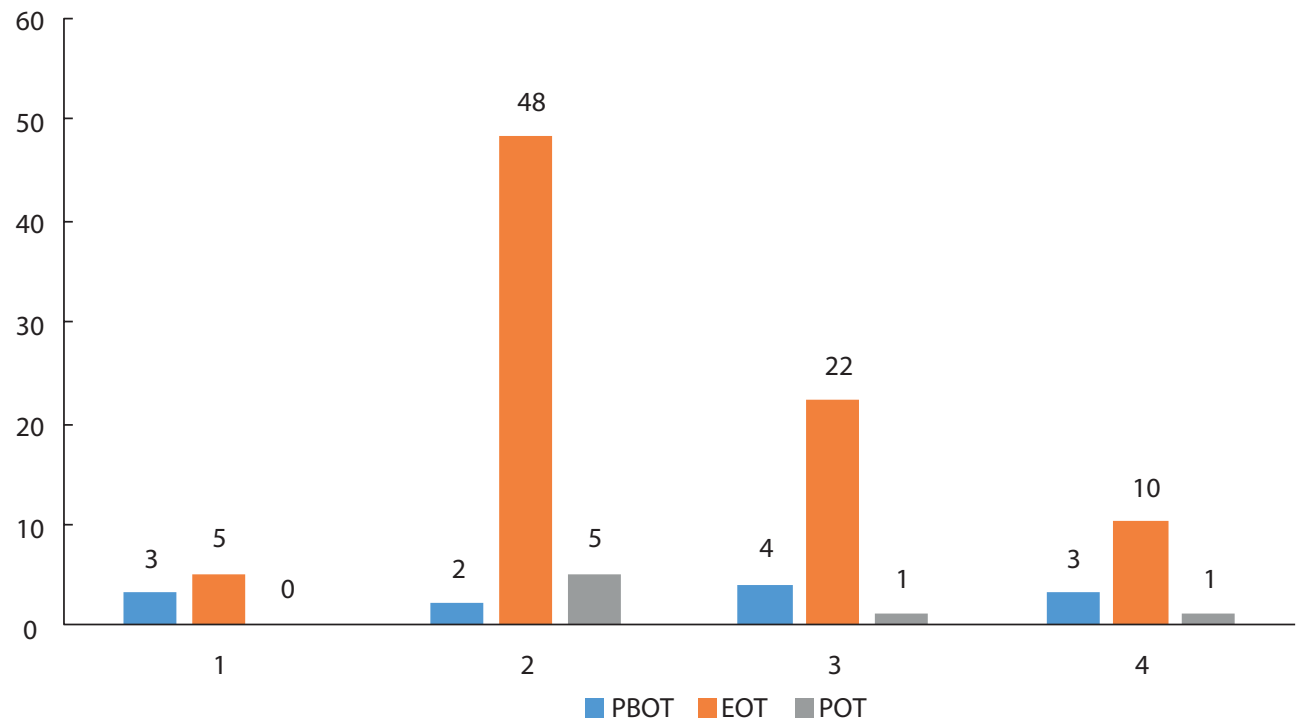

Fuente: elaboración propia. 
partamentos del Cesar y La Guajira, respectivamente, actualizaron dichos instrumentos ratificando como vocación del territorio la actividad minera, específicamente la de carbón. A su vez, los planes de desarrollo revisados de esta primera categoría, en las tres últimas vigencias, contemplan la minería como una actividad económica que se realiza en el municipio; sin embargo, no fue posible determinar en la revisión la relación entre la actividad y la generación de empleo, infraestructura, destinación de los recursos de regalías, entre otros. Es de anotar que los ocho municipios establecen otras actividades económicas como las del sector agropecuario y el turismo, sin indicar la compatibilidad entre estas y la minería. En los diagnósticos de los planes de desarrollo municipal, la preocupación por la pérdida de relevancia de actividades tradicionales en la región atribuidas al desarrollo de la actividad carbonífera es una constante (Anexo 1).

El caso 2 muestra que en estos territorios la vocación minera no es contemplada de forma expresa en sus instrumentos de ordenamiento, solo en 22 de los 55 instrumentos se reconoce esta actividad en su visión de largo plazo (Anexo 2). Al revisar el reconocimiento de la actividad minera en los planes de desarrollo municipal, es posible observar cómo esta aumenta entre periodos de gobierno; así, en el periodo 2008-2011 muestra una presencia del $54 \%$ de los PDM, seguido por un $72,7 \%$ en el periodo 2012-2015 y 69,1 \% en el periodo 2016-2019 (Anexo 2). En el estudio detallado de las dinámicas contenidas en los PDM del caso 2 fue posible observar que se encontraron 19 casos en los cuales el рот del municipio manifiesta no tener vocación minera, sin embargo, en los planes de desarrollo se reconoce esta actividad como una de las principales vocaciones económicas del municipio. Se encontraron 8 casos en los cuales el municipio dice tener vocación minera en su POT, pero los planes de desarrollo no desarrollan la actividad, como también se encontraron 13 municipios que manifiestan no tener destinado el suelo para uso minero y los planes de desarrollo no mencionan la actividad como fuente de desarrollo económico, pero reportan producción constante en el periodo 2011-2016.

El caso 3 muestra que el 59,3\% de los municipios no contemplaron en sus planes de ordenamiento territorial la minería en su visión de largo plazo contenida en el componente general del instrumento; sin embargo, se observa que la actividad minera aparece de forma intermitente en los últimos tres planes de desarrollo, a pesar de observarse producción continúa, según las estadísticas de producción. En el 37\% de los municipios que sí contemplan la minería como su vocación económica de largo plazo en sus рот, se observa que dicha vocación se comporta de forma irregular en los planes de desarrollo de los últimos tres periodos de gobierno, en los cuales esta ha sido desplazada en jerarquía por otras actividades económicas emergentes, todo esto a pesar que en el caso 3 se encuentran los municipios con mayor producción de carbón en el Norte de Santander, en los cuales la omisión aumenta a un $74,1 \%$ en el último periodo de gobierno (Anexo 3).

En el caso 4, la minería se encuentra de manera expresa en 9 de los 14 instrumentos de ordenamiento; asimismo, se evidenció que en los planes de desarrollo del periodo comprendido 
entre 2008-2011, el 50\% menciona la actividad minera de carbón en sus programas de gobierno; para el siguiente periodo, dicha mención como actividad económica principal pasa a un 78,6\%, y para el 2016-2019, dicha tendencia cambia y baja a $71,4 \%$, lo que evidencia una modificación de la vocación económica de estos municipios a través de sus últimos planes de desarrollo.

Un hallazgo relevante es que se pudo identificar que el $86 \%$ de los planes de ordenamiento territorial en los casos 1, 2, 3 y 4 han superado la vigencia establecida por la Ley 388 de 1997 para su visión de largo plazo, por lo que se recomienda realizar ejercicios de actualización y armonización de las dinámicas económicas, sociales, poblacionales y ambientales (figura 6). La principal implicación de ello para la minería, tal y como se estableció en párrafos anteriores, es que el desarrollo de la actividad con seguridad ha podido tener una influencia en el desarrollo físico de los territorios, así como también en la demanda de servicios por parte de la población residente o migrante a estos (Contreras, 2017).

Algo que llama la atención a nivel general en todos los casos, es que el 63\% de los municipios productores de carbón incluyó en los ejercicios presupuestales de los programas de ejecución de los PDM de los tres periodos de gobierno recursos provenientes de regalías como fuente de financiación de la acción pública municipal (figura 7); de esta manera, fue posible identificar su inclusión en las diferentes líneas estratégicas de los planes de desarrollo, haciendo énfasis en las líneas sociales (educación, salud, agua potable y saneamiento básico y vivienda, entre otros), pero sin mayor profundidad en la identificación de proyectos concretos orientados a la satisfacción de necesidades específicas para sus comunidades. Esta información se puede ver desagregada por caso en los anexos 1, 2, 3 y 4 .

Otro hallazgo importante es el alto grado de dependencia que presentan los municipios productores en sus ingresos totales de las

FIGURA 6. VIGENCIA DE LOS PLANES DE ORDENAMIENTO TERRITORIAL

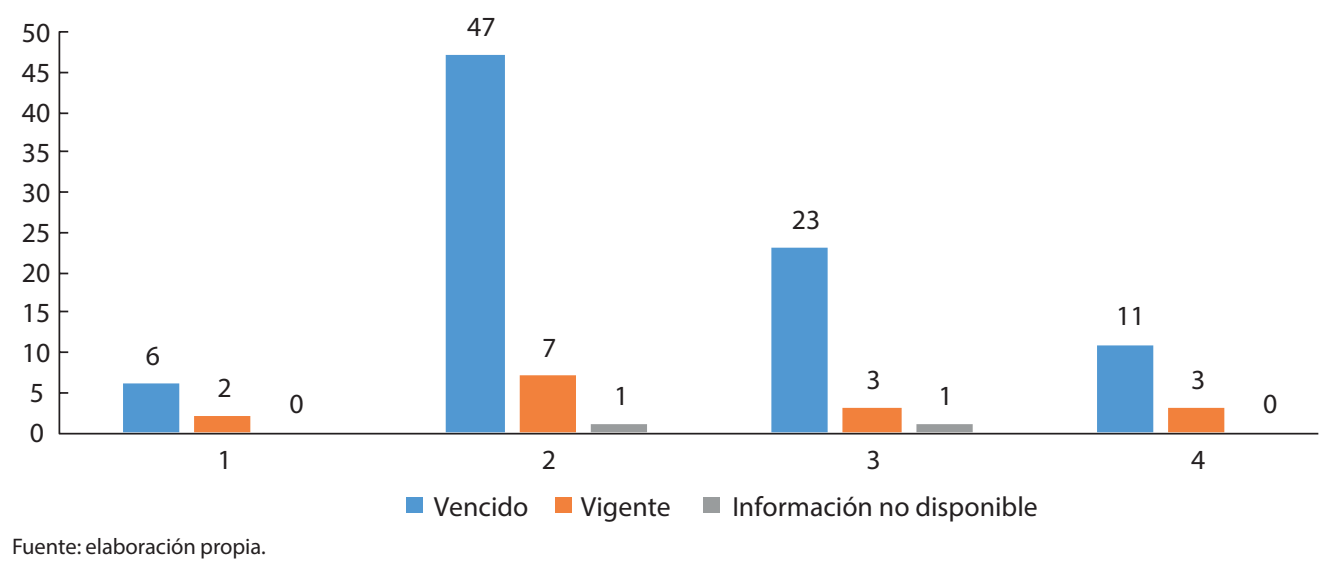


FIGURA 7. INCLUSIÓN DEL RUBRO DE REGALÍAS EN LOS PRESUPUESTOS DE LOS PLANES DE DESARROLLO

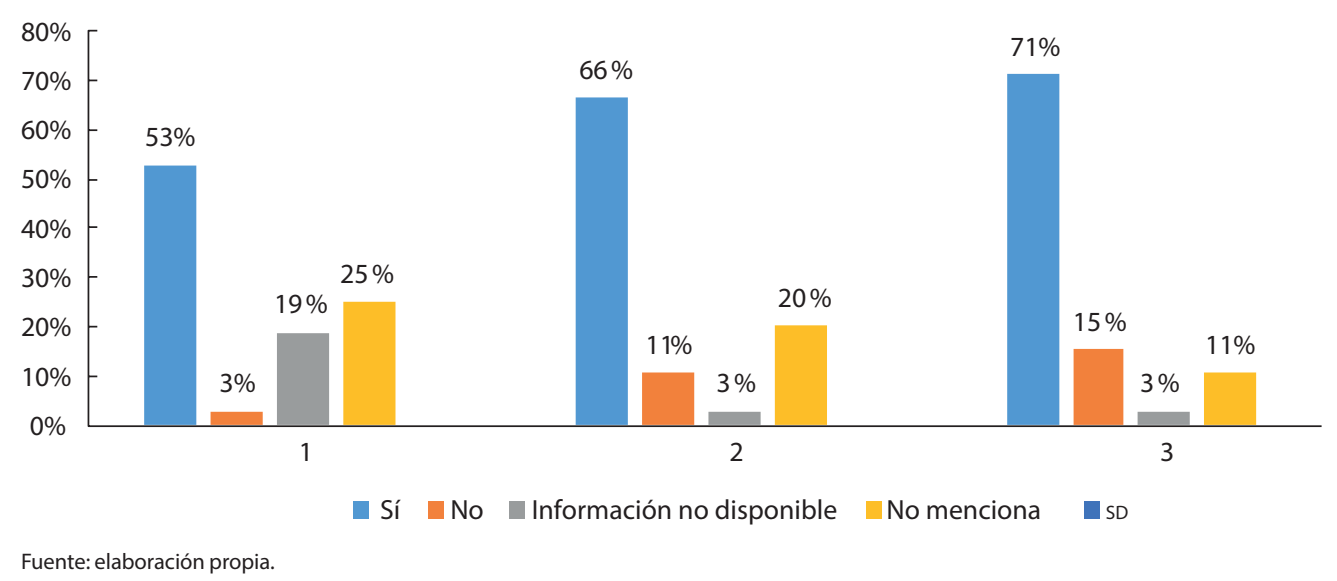

transferencias del Gobierno central y de los recursos provenientes de regalías. Los cálculos realizados a partir del índice de desempeño fiscal para el periodo de estudio (2011-2016) arrojaron que, en algunos casos, esta dependencia es superior al $75 \%$ del total de los ingresos de los municipios. En el caso 1 es posible constatar que esta dependencia es, en promedio, superior al $60 \%$ del total de los ingresos, siendo indiferente al volumen de producción registrada (Anexo 1). En el caso 2 el porcentaje de dependencia es superior al $62 \%$ y tiende a ser mayor en los municipios de menor producción carbonífera (Anexo 2). En el caso 3 la proporción en los ingresos municipales por transferencias y regalías aumenta en promedio a un $75 \%$ sobre el total de ingresos municipales, esta dependencia es independiente del volumen de producción, es decir que los municipios en los que se concentra la producción en el periodo estudiado presentan la misma dependencia que aquellos en los cuales la ac- tividad registra volúmenes modestos (Anexo 3). Los municipios aglutinados en el caso 4 presentan una dependencia promedio de $64 \%$ del peso de las regalías de la producción y las transferencias del nivel central sobre el total de sus ingresos (Anexo 4), en casos como los de El Tambo (87\%) y Buenos Aires (92\%) en el departamento del Cauca, que muestran la total dependencia de este tipo de recursos para la subsistencia del municipio. Un indicador por encima de $60 \%$ señala que la entidad territorial financia sus gastos, principalmente, con recursos de transferencias de la nación y regalías. El monto de las transferencias no incluye los recursos de cofinanciación, por lo que el rubro de regalías solo encierra la apropiación de los recursos de inversión directa, lo cual, si se conjuga con los resultados en términos de la vocación minera de los municipios, acelera la necesidad de actualizar la visión de largo plazo de estos territorios, así como la articulación de la vocación minera con actividades económicas 
complementarias que logren disminuir la dependencia de los recursos provenientes del nivel central y de la explotación del carbón.

Si bien es evidente el impacto que en materia presupuestal tiene la actividad en cuanto a regalías se refiere, es importante observar qué tipo de bienes y servicios adquieren los municipios con los recursos que son girados por este concepto, como también la relación que la inversión tiene con mejoramiento de la calidad de vida de sus habitantes. Para esta investigación, dicha verificación se realizó a través del instrumento "Mapa de Regalías", donde se puede visualizar a nivel municipal el monto, la línea de inversión a que corresponde el proyecto y su ubicación. Uno de los hallazgos principales de este punto es que en los casos 1, 2 y 4, un volumen significativo de recursos (aproximadamente un 52\% del total de las asignaciones aprobadas) está siendo orientado a la línea de inversión definida como transporte; para los casos 1, 2 y 4 fue la primera línea de inversión de los recursos, donde los proyectos que se ejecutan se encuentran asociados a la construcción y recuperación de la infraestructura vial municipal. La segunda línea en orden de importancia la constituyen los proyectos asociados a vivienda y territorio, que se enfocan a mejoramiento de infraestructura de acueducto y de zonas comunes. La tercera línea de inversión se encuentra orientada a promover la construcción y adecuación de actividades relativas al deporte y la cultura, donde los proyectos se orientan al desarrollo de infraestructura deportiva (Anexos 1, 2, 3 y 4). No obstante, un hallazgo importante es que en la priorización de inversión de los recursos las líneas asociadas a actividades relativas a la promoción social, en la mayoría de los casos, se encuentran en un segundo orden de importancia; líneas como la de inclusión social y reconciliación, y la de salud y protección social, se encuentran por debajo de las mencionadas al principio, tanto en monto de recursos como en el número de proyectos por desarrollar en los cuatro casos.

Lo anterior podría no ser importante si no se hubiera podido constatar que en la última medición disponible asociada al índice de necesidades básicas insatisfechas (NBI) (DANE, 2012), las zonas productoras presentan un indicador NBI promedio de 39,4, que se encuentra muy por encima del indicador nacional, el cual es 27,7. Durante esta revisión se observó una relación directa entre volumen de producción y altos índices de necesidades, es decir que a mayor producción los indicadores de NBI son más altos.

En el Anexo 1 se puede constatar cómo el caso 1 , que concentra el $91 \%$ de producción de carbón en el país, tiene un NBI promedio municipal del 53,4\%. En el Anexo 2 se observa que los municipios de Boyacá y Cundinamarca donde la explotación de carbón se concentra, los productores presentan un promedio de $37,4 \%$ de NBI; para el caso 3 el NBI promedio es de 40,3\% (Anexo 3), y para el caso 4 es de $37,2 \%$, el cual es, como se dijo anteriormente, el menor productor de carbón. Es posible que los casos 2, 3 y 4 puedan presentar un NBI más bajo debido a que sus actividades económicas son más diversas, lo que implicaría mejores condiciones de vida. Pero lo que sí se puede afirmar es que donde la actividad carbonífera se desarrolla esta se puede asociar de forma directa con la presencia de altos índices de NBI. 
Un último indicador que se incorporó al análisis de los municipios con presencia de la actividad carbonífera fue el número de registros validados del Sisben, este indicador se involucró con un doble propósito. El primero asociado a que como índice de estándar de vida permite hacerse a una idea de los hogares con algún tipo de carencia relativa a la salud, educación, vivienda y vulnerabilidad.

El segundo, al ser un índice compuesto por la verificación y actualización de registros, es dinámico, y al contar registros y personas asociadas al hogar permite tener una proyección de personas por año que podrían ser objeto de la ayuda del Estado; dicho registro, al ser comparado con las proyecciones de población del DANE podría establecer una proporción simple de personas del municipio, potenciales beneficiarias de la oferta social del Estado.

Para los municipios productores de carbón, tal y como se ve en la figura 8 , la población
Sisben se encuentra en aumento, en el año 2011 los registros contemplan en promedio un $63 \%$ de población total en condiciones de vulnerabilidad, este indicador aumenta hasta el 2016 con un $71 \%$ de personas registradas en el Sisben como proporción de la población total proyectada para los municipios de los casos de estudio.

Es importante resaltar que los municipios con mayor porcentaje de población registrada en el Sisben se encuentran en el caso 1, en la mayoría de estos municipios el número de registros de personas en el Sisben se mantuvo en aumento a lo largo de los ańos observados y superó en gran medida a la proyección de población registrada por el DANE a nivel municipal (Anexo 1); en los casos 2 y 3 los registros de población en Sisben se mantuvieron constantes, si bien no superaron su población proyectada, el porcentaje de población en Sisben estuvo por encima del 68\% en la

FIGURA 8. RELACIÓN POBLACIÓN SISBEN FRENTE A POBLACIÓN TOTAL POR AÑOS

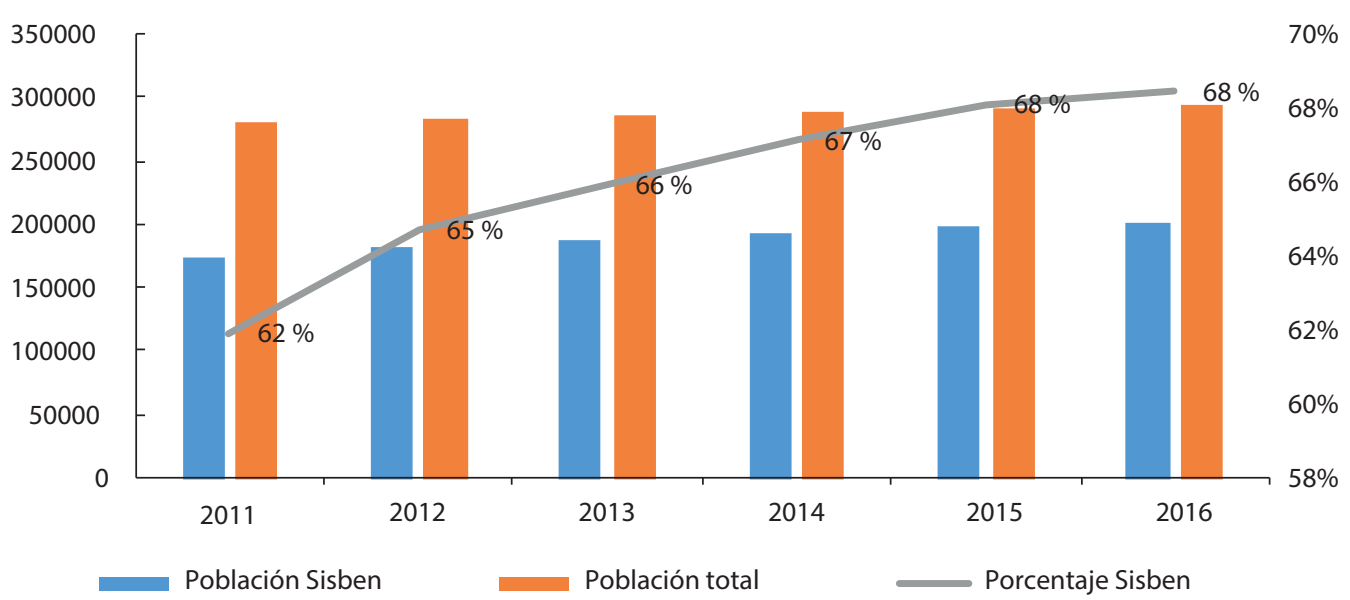

Fuente: elaboración propia. 
mayoría de los municipios; para el caso 4, es posible observar cómo el número de registros de personas en el Sisben pasó de representar un 78,7\% en el 2011 a un $97,5 \%$ en el 2016 . Por ejemplo, en el caso 1 se destaca La Jagua de Ibirico, en donde la población registrada en la herramienta de focalización constituye un $146 \%$ del total de población proyectada por el DANE para el periodo de estudio (Anexo 1).

Cuando se compara con la producción de carbón, la población inscrita en el Sisben tiende a guardar relación con los picos de producción, la figura 9 muestra cómo, a medida que la producción aumenta, la población inscrita también tiende a aumentar.

Un último hallazgo que vale la pena mencionar es que al revisar uno a uno los municipios productores se encuentra que, cuando la producción sube, el porcentaje de población inscrita en el Sisben se acentúa; pero cuando la producción disminuye, la población inscrita continúa incrementándose, como se evidencia en la figura 9. Esto puede estar relacionado con los movimientos migratorios que genera la actividad.

\section{REFERENCIAS}

Acemoglu, D. y Robinson, J. A. (2012). Why Nations Fail. London: Profile Books.

Acto Legislativo 005 (2011). Por el cual se constituye el Sistema General de Regalías, se modifican los artículos 360 y 361 de la Constitución Política y se dictan otras disposiciones sobre el Régimen de Regalías y Compensaciones. Recuperado de http://www.alcaldiabogota.gov.co/sisjur/normas/Norma1.jsp?i=43391

Agencia Nacional de Mineria (ANM) (2018). Ficha Mineral - Carbón 2018. Bogotá: ANM.

British Petroleum (вр) (2019). Statistical Review of World Energy 2019 (68). вр.

Campbell, B. (ed.) (2009). Mining in Africa. Regulation and development. London: Pluto Press, International Development Research Centre.

FIGURA 9. RELACIÓN POBLACIÓN SISBEN FRENTE A PRODUCCIÓN POR AÑOS

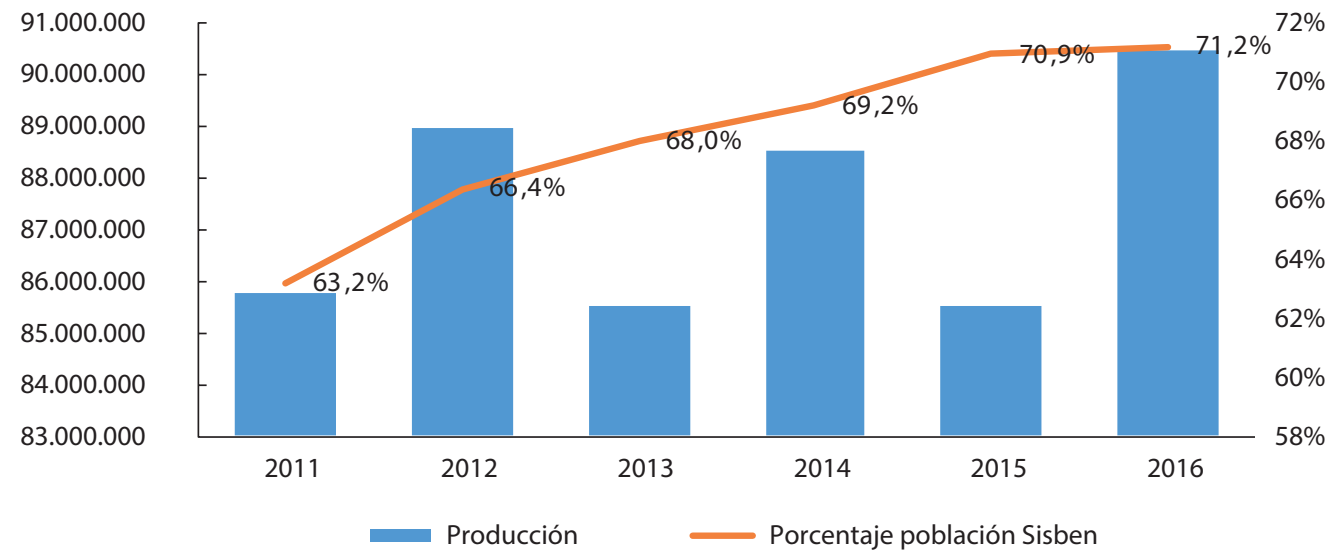

Fuente: elaboración propia. 
Consejo Nacional de Política Económica y Social (Conpes) (2008). Documento Conpes Social 117 de 2008: actualización de los criterios para la determinación, identificación y selección de beneficiarios de programas sociales. Bogotá: Conpes. Contreras, Y. (2017). 20 años de ordenamiento territorial en Colombia: experiencias, desafios y herramientas para los actores territoriales. Bogotá: Universidad Nacional de Colombia.

Departamento Administrativo Nacional de Estadística (DANe) (2005). Boletín 1 Censo General 2005 Necesidades Básicas Insatisfechas. Recuperado de https://www.dane.gov.co/files/investigaciones/ boletines/censo/Bol_nbi_censo_2005.pdf

Departamento Administrativo Nacional de Estadística (DANE) (2012). Necesidades básicas insatisfechas (NBI), por total, cabecera y resto, según departamento y nacional a 30 junio de 2012. Recuperado de https://www.dane.gov.co/index.php/ estadisticas-por-tema/pobreza-y-condicionesde-vida/necesidades-basicas-insatisfechas-nbi

Departamento Administrativo Nacional de Estadística (DANE) (2016a). Necesidades básicas insatisfechas (NBI). Recuperado de https://www.dane.gov. co/index.php/estadisticas-por-tema/pobrezay-condiciones-de-vida/necesidades-basicas-insatisfechas-nbi

Departamento Administrativo Nacional de Estadística (DAne) (2016b). Boletín Técnico Pobreza monetaria 2015: La Guajira. Recuperado de https://www.dane.gov.co/files/investigaciones/ condiciones_vida/pobreza/2015/Guajira_Pobreza_2015.pdf

Departamento Administrativo Nacional de Estadística (DANE) (2016c). Boletín Técnico Pobreza monetaria 2015: Boyacá. Recuperado de https://www. dane.gov.co/files/investigaciones/condiciones_ vida/pobreza/2015/Boyaca_Pobreza_2015.pdf
Departamento Nacional de Planeación (DNP) (2007a). El proceso de planificación en las entidades territoriales: el plan de desarrollo y sus instrumentos para la gestión 2008-2011. Recuperado de http://200.93.163.76:8080/moodledata/246/ Planeacion_PDM.pdf

Departamento Nacional de Planeación (DNP) (2007b). Las regalias en Colombia. Recuperado de http:// www.simco.gov.co/simco/documentos/Regalias/ ACT_cartilla_regalias.pdf

Departamento Nacional de Planeación (DNP) (2013). Fortalecimiento de la gestión de las finanzas públicas en Colombia. Recuperado de https://colaboracion.dnp.gov.co/CDT/Desarrollo\%20Territorial/ PROYECTO\%20SECO\%20-\%20CID\%20unAL.pdf Departamento Nacional de Planeación (DNP) (2014a). Evaluación del desempeño integral de los municipios y distritos, vigencia 2013. Recuperado de http://colaboracion.dnp.gov.co/cdt/ desarrollo\%20territorial/docuemnto $\% 20$ desempe $\%$ C3\%B1o\%20integral\%202013.pdf Departamento Nacional de Planeación (DNP) (2014b). Evaluación del desempeño integral de los municipios y distritos, vigencia 2013. Recuperado de http://colaboracion.dnp.gov.co/cdt/ desarrollo\%20territorial/docuemnto $\% 20$ desempe $\%$ C3\%B1o\%20integral\%202013.pdf

Departamento Nacional de Planeación (DNP) (2015a). ¿Qué es el Sisben? Recuperado de https:// www.sisben.gov.co/Informaci\%C3\%B3n/ ElSisb\%C3\%A9n.aspx\#.wirDbvphDiu

Departamento Nacional de Planeación (DNP) (2015b). Desarrollo territorial. Recuperado de https:// www.dnp.gov.co/programas/desarrollo-territorial/Paginas/desarrollo-territorial.aspx

Departamento Nacional de Planeación (DNP) (2015c). Plan Nacional de Desarrollo 2014-2018. Recuperado de https://colaboracion.dnp.gov.co/ 
CDT/PND/PND\%202014-2018\%20Tomo\%20

$1 \% 20$ internet.pdf

Departamento Nacional de Planeación (DNP) (2105d).

Evaluación del desempeño integral de los municipios y distritos, vigencia 2014. Recuperado de https://colaboracion.dnp.gov.co/CDT/Desarrollo\%20Territorial/Desempe\%C3\%B1o\%20 integral\%202014.pdf

Economía Colombiana (2015). ¿Cuál es el Plan?: un análisis a fondo de los Planes Nacionales de Desarrollo en Colombia: su historia, su presente y su futuro, (344).

Frederiksen, T. (2019). Political settlements, the mining industry and corporate social responsibility in developing countries. The Extractive Industries and Society, 6, 162-170.

Gudynas, E. (2000). Los limites de la sustentabilidad débil, y el tránsito desde el capital natural al patrimonio ecológico. Recuperado de http://www. ecologiasocial.com/publicacionesclaes/GudynasCapitalNaturalVz00.pdf

Hernández, C. (2018). La evolución del concepto de sostenibilidad y su incidencia en la educación ambiental. Recuperado de https://www.researchgate.net/publication/279639150_La_evolucion_del_concepto_de_sostenibilidad_y_su_incidencia_en_la_educacion_ambiental

Informe Brundtland, nuestro futuro común (1987). Reporte de la comisión mundial sobre medio ambiente y desarrollo. Organización de las Naciones Unidas, Nueva York. Recuperado de https://sustainabledevelopment.un.org/content/ documents/5987our-common-future.pdf

Instituto de Estudios Ambientales para el Desarrollo (IDEADE) (2015). Análisis de instrumentos de ordenamiento y planeación territorial en las tres ventanas de estudio; Ciénaga de la Virgen, Ciénaga de Zapatosa y complejo de humedales
Paz de Ariporo-Hato Corozal, Facultad de Estudios Ambientales y Rurales. Bogotá: Universidad Javeriana, Instituto de Investigación de Recursos Biológicos Alexander von Humboldt.

Julio, J. y Herrera, D. (2016). Los instrumentos de ordenamiento territorial y minería a gran escala en Colombia: la reglamentación del uso del suelo minero en los Planes de Ordenamiento Territorial de los municipios con mayor producción carbonifera. Minería y Desarrollo. Historia $y$ desarrollo de territorio minero (t. V). Bogotá: Universidad Externado de Colombia.

Kommadath, S. y Rath, A. (2012). Fuzzy logic based approach to assess sustainable development of the mining and minerals sector. Sustainable Development, 20(6), 386-399.

Leal, G. (2006). Debate sobre la sostenibilidad. Recuperado de https://www.javeriana.edu.co/Facultades/Arquidiseno/maeplan/publicaciones/documents/DebatesobrelaSostenibilidad_000.pdf

Ley 141 (1994). Por la cual se crean el Fondo Nacional de Regalías, la Comisión Nacional de Regalías, se regula el derecho del Estado a percibir regalías por la explotación de recursos naturales no renovables, se establecen las reglas para su liquidación y distribución y se dictan otras disposiciones. Recuperado de http://www.alcaldiabogota.gov. co/sisjur/normas/Norma1.jsp?i=9153

Ley 388 (1997). Por la cual se modifica la Ley 9a de 1989, y la Ley $3^{a}$ de 1991 y se dictan otras disposiciones. Recuperado de http://www.minvivienda.gov.co/LeyesMinvivienda/0388\%20 -\%201997.pdf

Ley 617 (2000). Por la cual se reforma parcialmente la Ley 136 de 1994, el Decreto Extraordinario 1222 de 1986, se adiciona la Ley Orgánica de Presupuesto, el Decreto 1421 de 1993, se dictan otras normas tendientes a fortalecer la descen- 
tralización, y se dictan normas para la racionalización del gasto público nacional. Recuperado de http://www.secretariasenado.gov.co/senado/ basedoc/ley_0617_2000.html

Mancini, L. y Sala, S. (2018). Social impact assessment in the mining sector: Review and comparison of indicators frameworks. Resources Policy, 57(2018), 98-111.

McEwan, C., Mawdsley, E., Banks, G. y Scheyvens, R. (2017). Enrolling the private sector in community development: Magic bullet or sleight of hand? Development Change, (48), 28-53.

Mining, Minerals and Sustainable Development (MMsD) (2012). Abriendo la brecha. Recuperado de https://www.iied.org/mining-minerals-sustainable-development-mmsd

Programa de las Naciones Unidas para el Desarrollo (PNUD) (2015). Evaluación del sistema general de regalías. Cuadernos del PNUD. Bogotá: PNUD.

Ramírez, C., Castro, J., Restrepo, J. y Barbosa, N. (2015). Orientaciones para la revisión y ajuste de los planes de ordenamiento territorial del departamento del Meta. Pase al desarrollo 2013 2014. Bogotá: UNFPA, Universidad Externado de Colombia.
Unidad de Planeación Minero Energética (UPME) (2005). La cadena del carbón en Colombia. Recuperado de http://www.upme.gov.co/docs/ cadena_carbon.pdf

Unidad de Planeación Minero Energética (UPME) (2014). Indicadores de la minería en Colombia. Recuperado de http://www.upme.gov.co/Docs/ Plan_Minero/2014/Indicadores $\% 20 \mathrm{de} \% 20$ la\%20Miner\%C3\%ADa\%20en\%20Colombia.pdf

van Teijlingen, K. (2016). The "will to improve" at the mining frontier: neo-extractivism, development and governmentality in the Ecuadorian Amazon. The Extractive Industries and Society, (3), 902-911.

Zapata, J. G. (2013). Instituciones, capacidades y competencias de las autoridades departamentales y municipales. Bogotá: Unidad de Planeación Minero Energética, Centro Interdisciplinario de Estudios sobre el Desarrollo. 


\section{ANEXO 1. INFORMACIÓN DE SOPORTE - CASO 1}

FIGURA 1. DEPENDENCIA PROMEDIO DE LAS TRANSFERENCIAS Y LAS REGALÍAS EN LOS RECURSOS DE LOS MUNICIPIOS PRODUCTORES DE CARBÓN DEL CESAR Y LA GUAJIRA FRENTE A PRODUCCIÓN PROMEDIO (2011-2016)

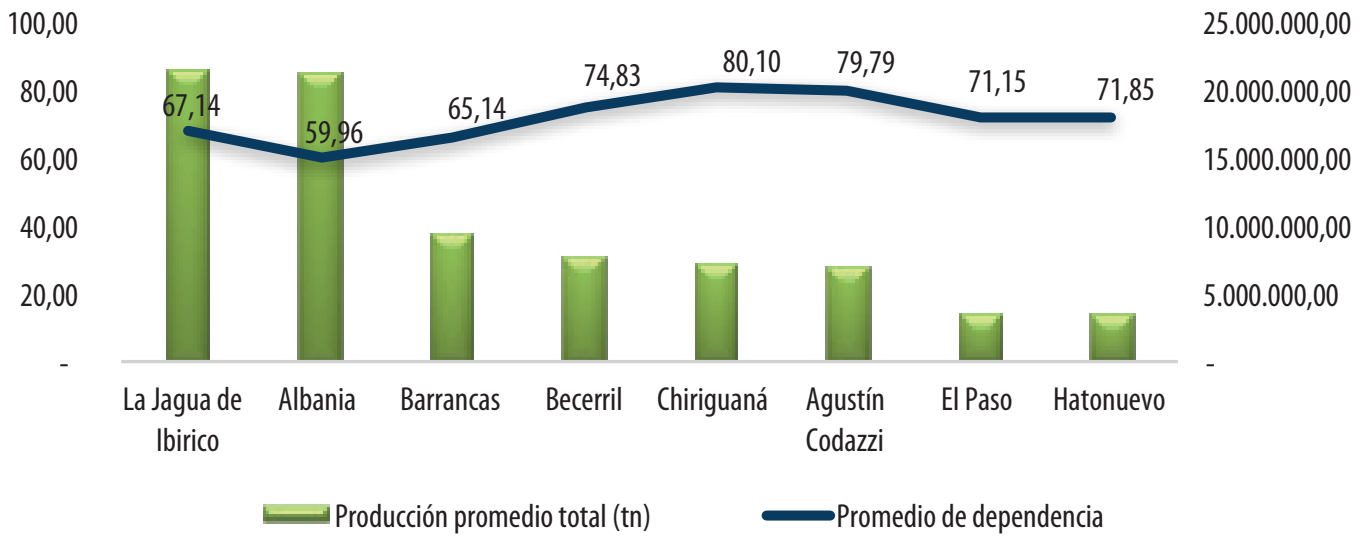

Fuente: elaboración propia.

TABLA 1. COMPARATIVO ENTRE LA VOCACIÓN DEL POT Y LAS ACTIVIDADES MENCIONADAS DEL PLAN DE DESARROLLO MUNICIPAL DE LOS AÑOS 2008, 2012, 2016

\begin{tabular}{|l|c|c|c|c|}
\hline \multicolumn{1}{|c|}{ Municipio } & Vocación POT (Minera) & PD 2008-2011 & PD 2012-2015 & PD 2016-2019 \\
\hline Agustín Codazzi & No & Sí & Sí & Sí \\
\hline Albania & Sí & Sí & Sí & Sí \\
\hline Barrancas & Sí & SD & Sí & Sí \\
\hline Becerril & Sí & Sí & Sí & SD \\
\hline Chiriguaná & Sí & Sí & Sí & Sí \\
\hline El Paso & Sí & Sí & Sí & Sí \\
\hline Hato Nuevo & Sí & Sí & Sí & Sí \\
\hline La Jagua de lbirico & Sí & Sí & Sí & \\
\hline
\end{tabular}

SD: $\sin$ datos

Fuente: elaboración propia. 
FIGURA 2. PRESENCIA DE VOCACIÓN MINERA EN POT Y EN LOS PLANES DE DESARROLLO (2008-2019)

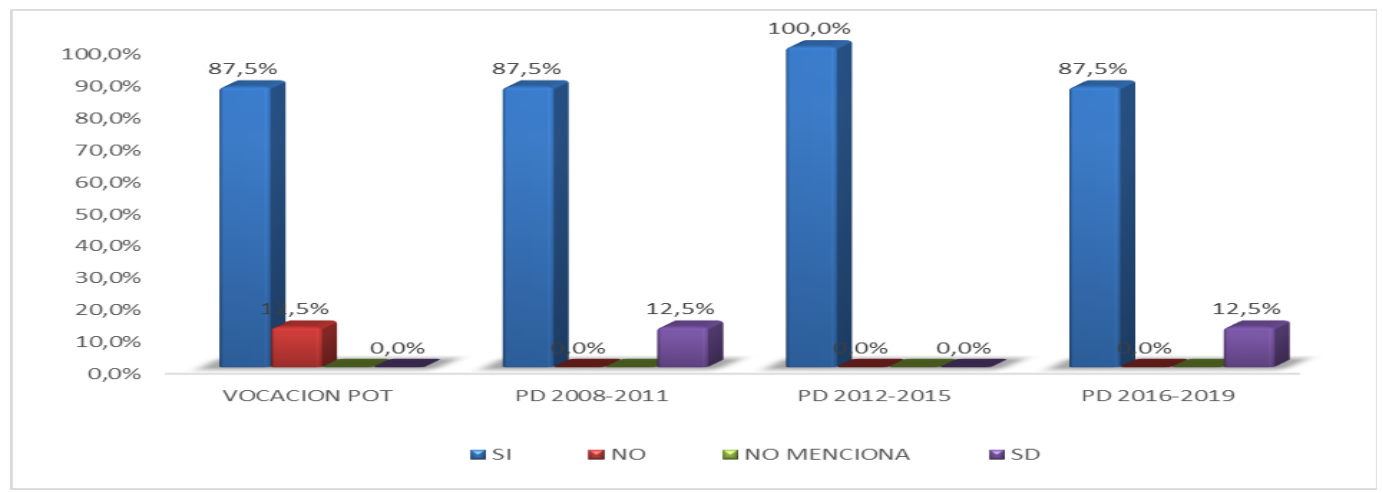

Fuente: elaboración propia.

FIGURA 3. INCLUSIÓN DEL RUBRO DE REGALÍAS EN LOS PRESUPUESTOS MUNICIPALES DE LOS PLANES DE DESARROLLO (2008-2019)

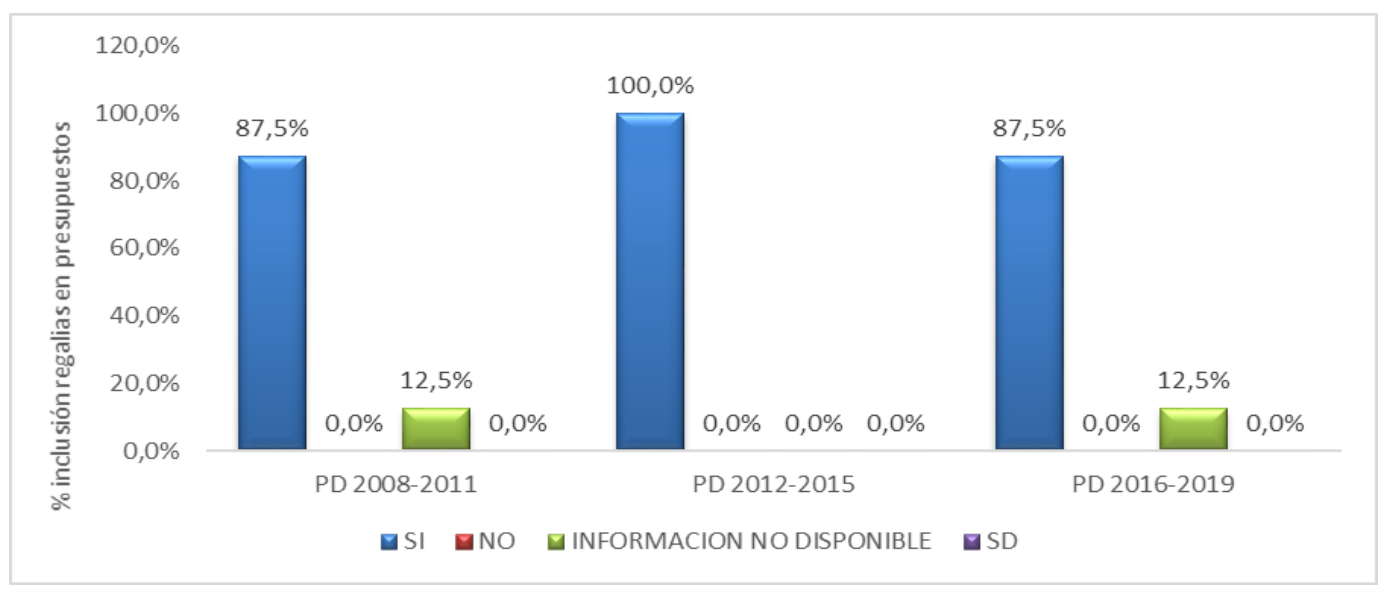

Fuente: elaboración propia. 
TABLA 2. LÍNEAS DE INVERSIÓN DE RECURSOS APROBADOS DE INVERSIÓN DIRECTA DE REGALÍAS POR MUNICIPIO (2011-2016)

\begin{tabular}{|c|c|c|c|c|c|c|c|}
\hline Departamento & Alcaldía & Línea 1 & $\%$ & Línea 2 & $\%$ & Línea 3 & $\%$ \\
\hline \multirow{5}{*}{ Cesar } & Agustín Codazzi & Transporte & $32 \%$ & $\begin{array}{l}\text { Deporte y } \\
\text { Recreación }\end{array}$ & 26 & $\begin{array}{l}\text { Vivienda, Ciudad } \\
\text { y Territorio }\end{array}$ & 16 \\
\hline & Becerril & Transporte & $29 \%$ & $\begin{array}{l}\text { Vivienda, Ciudad } \\
\text { y Territorio }\end{array}$ & 28 & $\begin{array}{l}\text { Salud y Protec- } \\
\text { ción Social }\end{array}$ & 21 \\
\hline & Chiriguaná & Transporte & $33 \%$ & $\begin{array}{l}\text { Deporte y } \\
\text { Recreación }\end{array}$ & 31 & $\begin{array}{l}\text { Vivienda, Ciudad } \\
\text { y Territorio }\end{array}$ & \\
\hline & El Paso & Transporte & $31 \%$ & Educación & 20 & $\begin{array}{l}\text { Vivienda, Ciudad } \\
\text { y Territorio }\end{array}$ & 17 \\
\hline & $\begin{array}{l}\text { La Jagua de } \\
\text { Ibirico }\end{array}$ & $\begin{array}{l}\text { Vivienda, Ciu- } \\
\text { dad y Territorio }\end{array}$ & $27 \%$ & Transporte & 23 & $\begin{array}{l}\text { Inclusión Social y } \\
\text { Reconciliación }\end{array}$ & 13 \\
\hline \multirow{3}{*}{ La Guajira } & Albania & $\begin{array}{l}\text { Deporte y Re- } \\
\text { creación }\end{array}$ & $40 \%$ & $\begin{array}{l}\text { Inclusión Social y } \\
\text { Reconciliación }\end{array}$ & 22 & $\begin{array}{l}\text { Vivienda, Ciudad } \\
\text { y Territorio }\end{array}$ & 17 \\
\hline & Barrancas & Transporte & $32 \%$ & Educación & 26 & $\begin{array}{l}\text { Ambiente y De- } \\
\text { sarrollo Soste- } \\
\text { nible }\end{array}$ & 11 \\
\hline & Hato Nuevo & Transporte & $49 \%$ & $\begin{array}{l}\text { Vivienda, Ciudad } \\
\text { y Territorio }\end{array}$ & 23 & $\begin{array}{l}\text { Inclusión Social y } \\
\text { Reconciliación }\end{array}$ & 11 \\
\hline
\end{tabular}

Fuente: elaboración propia con base en Mapa de regalías.

FIGURA 4. VOLUMEN DE PRODUCCIÓN (PROM. 2011-2016) FRENTE A ÍNDICE NBI MUNICIPAL, DEPARTAMENTAL (LA GUAJIRA) Y NACIONAL (2011)

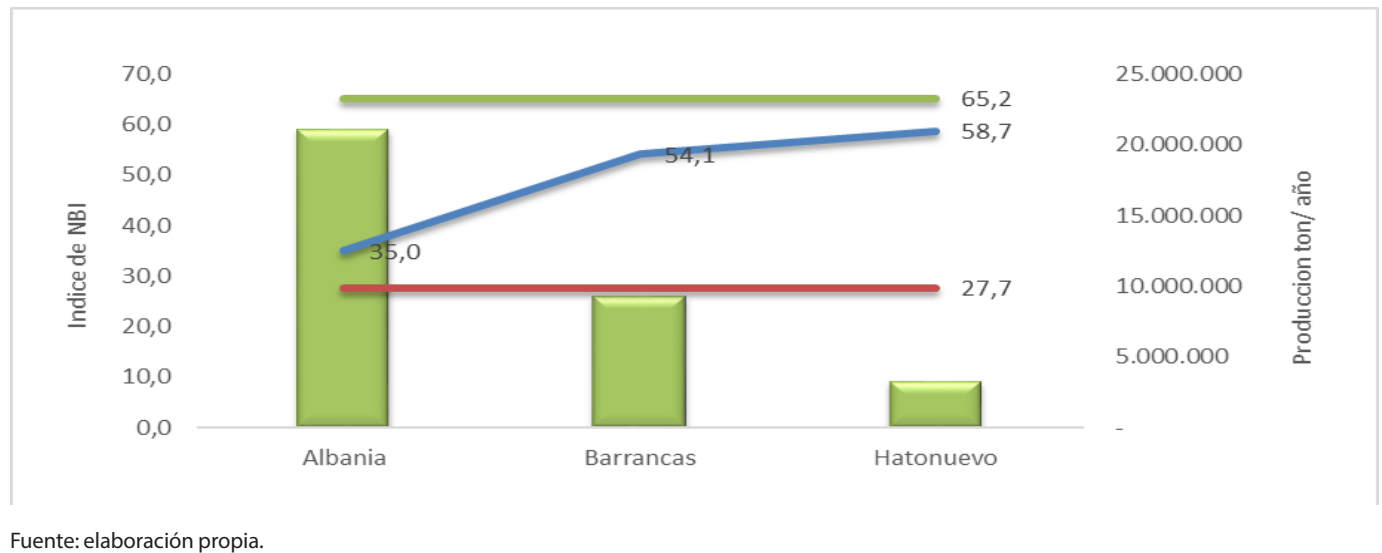


FIGURA 5. VOLUMEN DE PRODUCCIÓN (PROM. 2011-2016) FRENTE A ÍNDICE NBI MUNICIPAL, DEPARTAMENTAL (CESAR) Y NACIONAL (2011)

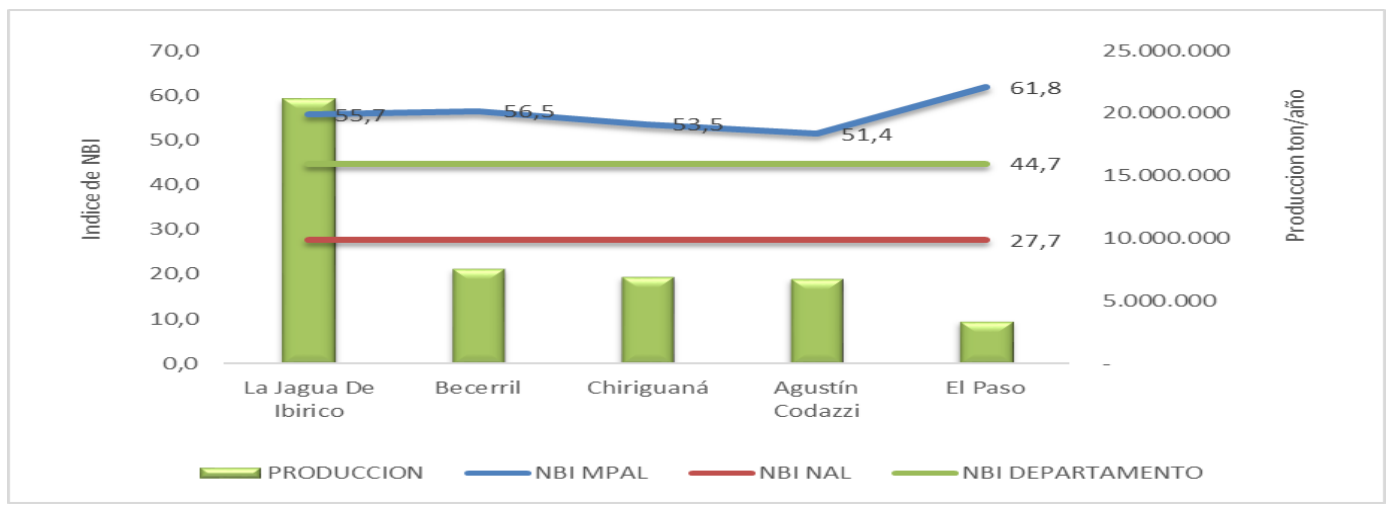

Fuente: elaboración propia.

FIGURA 6. PROMEDIO DE PRODUCCIÓN DEL PORCENTAJE DE POBLACIÓN SISBEN 2011-2016 DE LOS MUNICIPIOS PRODUCTORES DE CARBÓN DEL CESAR Y LA GUAJIRA

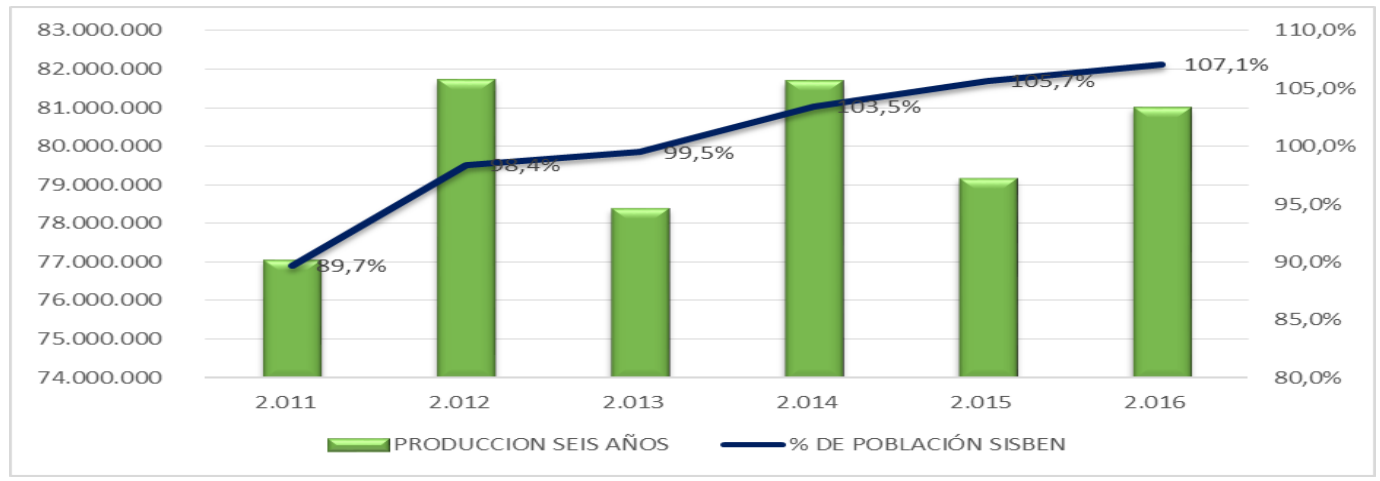

Fuente: elaboración propia. 
FIGURA 7. PROMEDIO DE PRODUCCIÓN DE LOS MUNICIPIOS DEL CESAR Y LA GUAJIRA FRENTE A PORCENTAJE PROMEDIO DE POBLACIÓN SISBEN 2011-2016

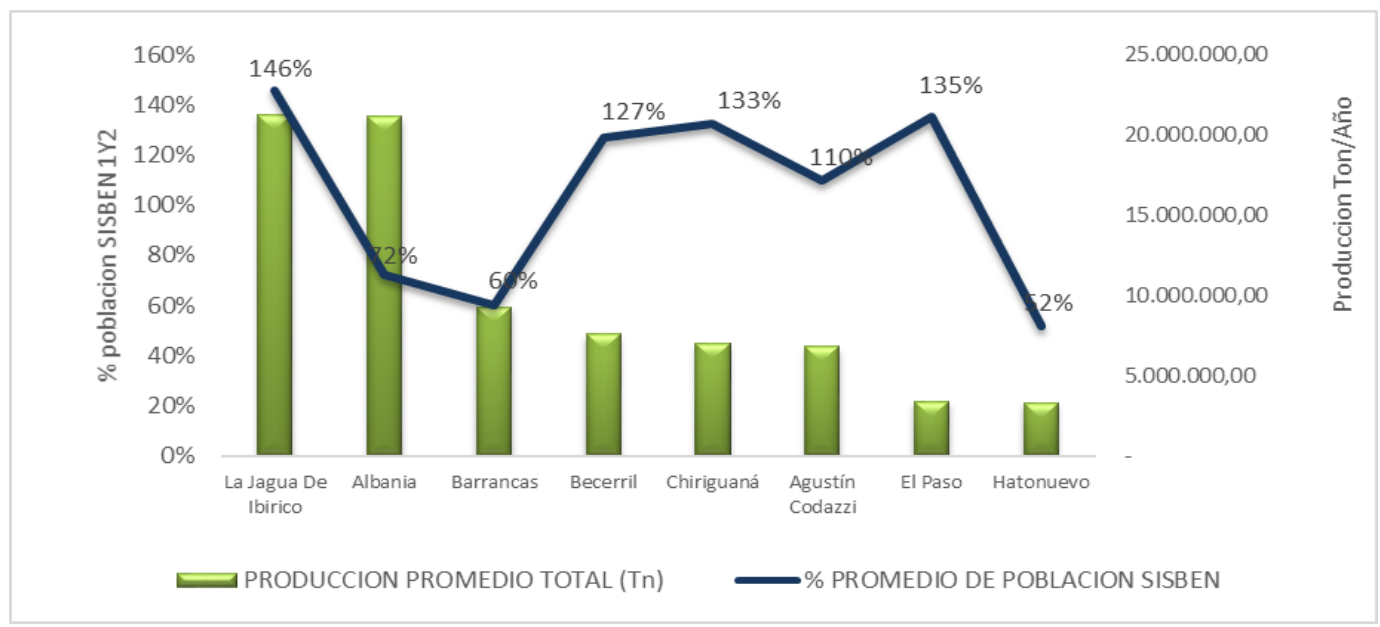

Fuente: elaboración propia.

\section{ANEXO 2. INFORMACIÓN DE SOPORTE - CASO 2}

FIGURA 1. PORCENTAJE DE REGALÍAS EN LOS PRESUPUESTOS MUNICIPALES - CASO 2

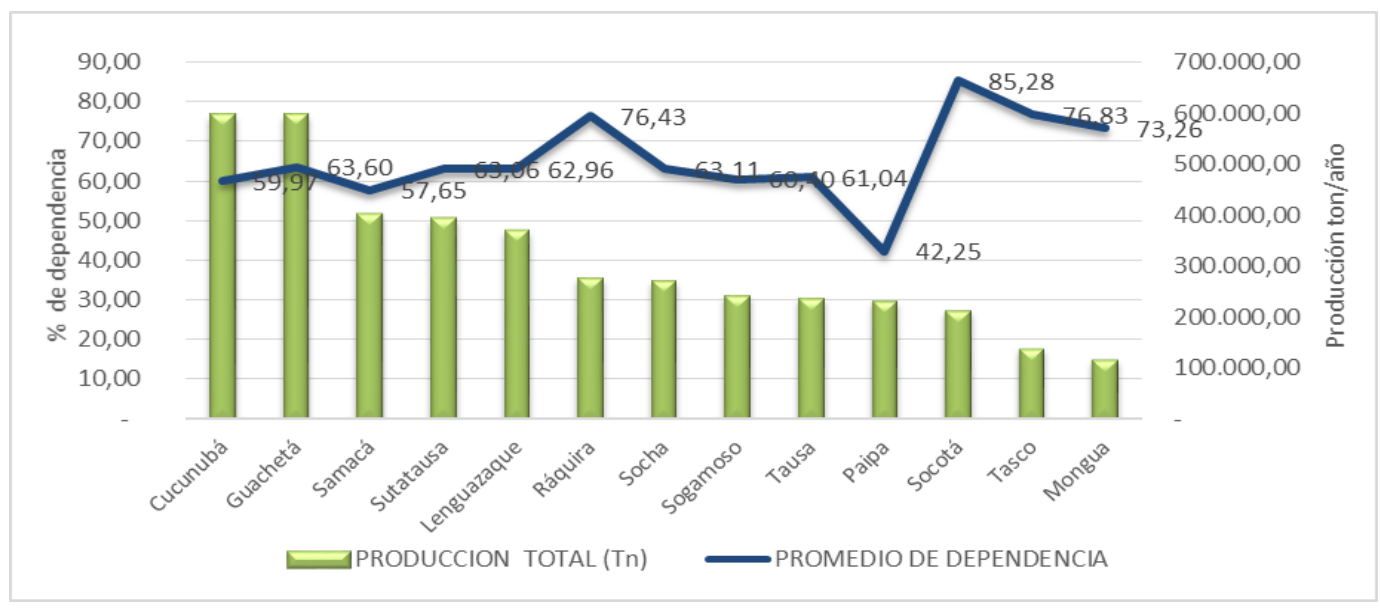

Fuente: elaboración propia. 
FIGURA 2. PORCENTAJE DE REGALÍAS EN LOS PRESUPUESTOS MUNICIPALES - CASO 2

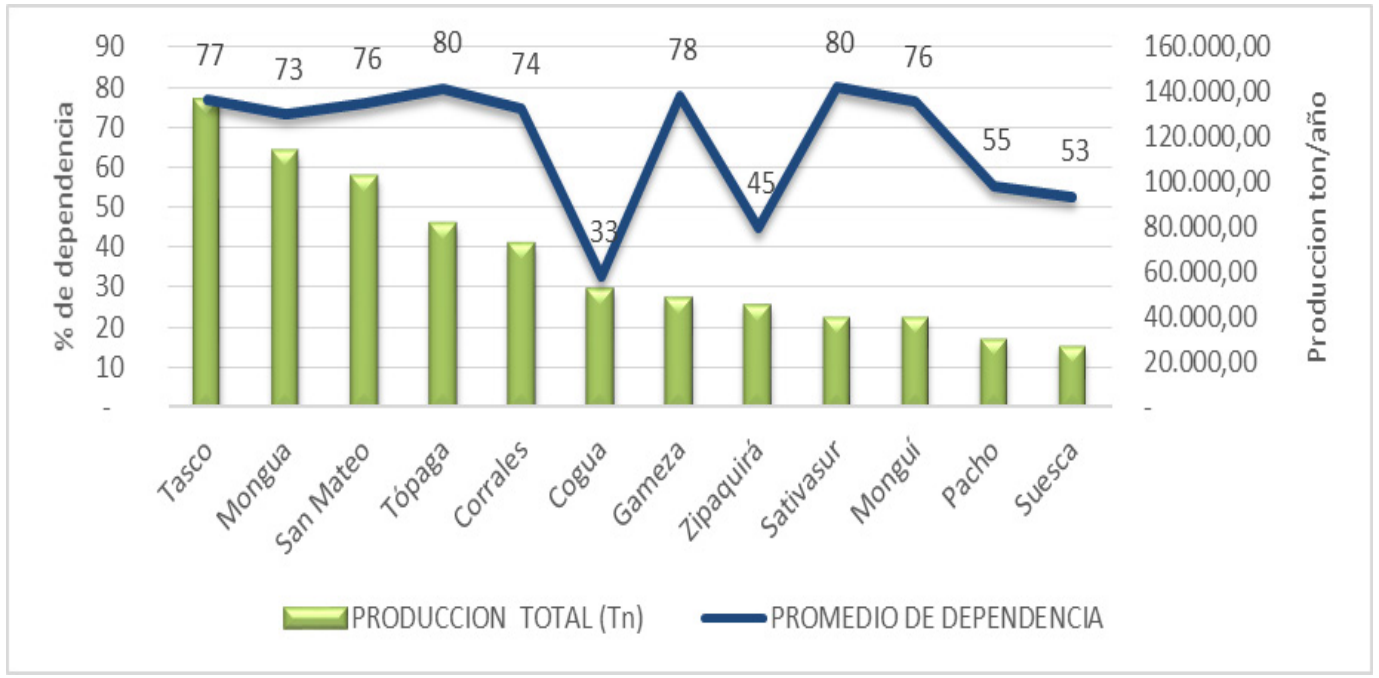

Fuente: elaboración propia.

FIGURA 3. PORCENTAJE DE REGALÍAS EN LOS PRESUPUESTOS MUNICIPALES - CASO 2

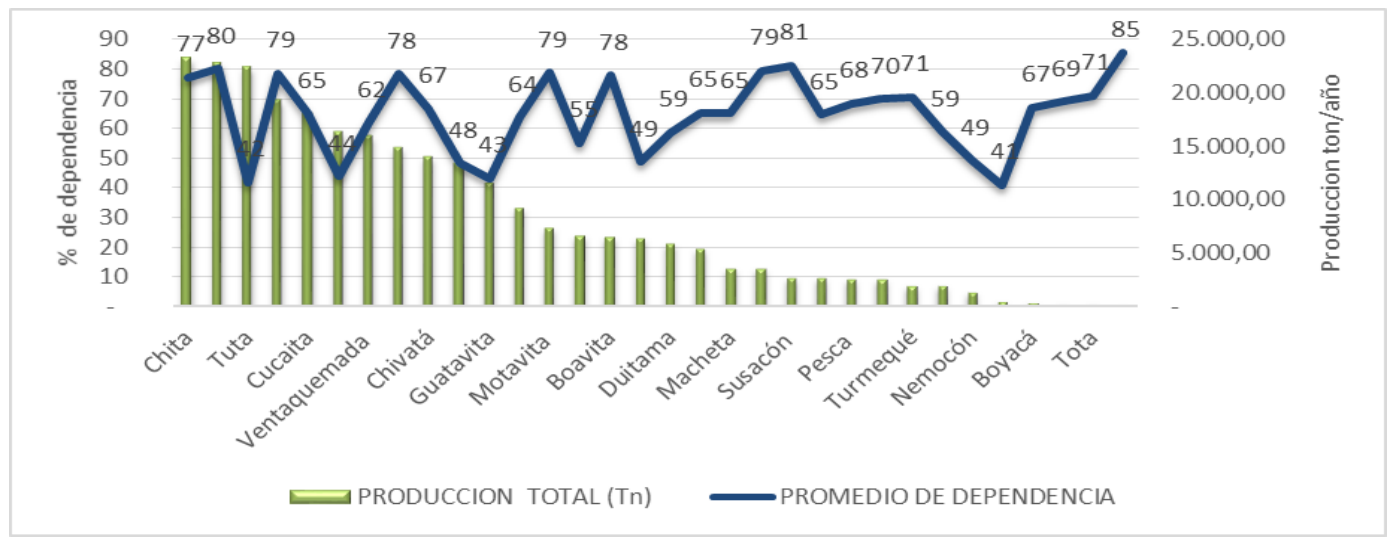

Fuente: elaboración propia. 
TABLA 1. COMPATIBILIDAD ENTRE EL POT Y LOS PLANES DE DESARROLLO CON RESPECTO A LA ACTIVIDAD MINERA DE CARBÓN EN EL CASO 2

\begin{tabular}{|c|c|c|c|c|}
\hline Municipio & Vocación POT & PD 2008-2011 & PD 2012-2015 & PD 2016-2019 \\
\hline Cucunubá & Sí & Sí & Sí & Sí \\
\hline Guachetá & Sí & No & No & Sí \\
\hline Samacá & Sí & Sí & Sí & Sí \\
\hline Sutatausa & Sí & Sí & Sí & Sí \\
\hline Lenguazaque & Sí & Sí & Sí & Sí \\
\hline Ráquira & Sí & Sí & Sí & Sí \\
\hline Socha & Sí & $\mathrm{Sd}$ & Sí & Sí \\
\hline Sogamoso & Sí & Sí & Sí & Sí \\
\hline Tausa & Sí & Sí & Sí & No \\
\hline Paipa & Sí & Sí & Sí & Sí \\
\hline Socotá & Sí & Sí & Sí & Sí \\
\hline Tasco & Sí & Sí & Sí & Sí \\
\hline Mongua & No & $\mathrm{Sd}$ & Sí & Sí \\
\hline San Mateo & No & Sí & Sí & Sí \\
\hline Tópaga & Sí & $\mathrm{Sd}$ & Sí & Sí \\
\hline Corrales & Sí & Sí & Sí & Sí \\
\hline Cogua & No & No & Sí & Sí \\
\hline Gámeza & Sí & Sí & Sí & Sí \\
\hline Zipaquirá & Sí & No & Sí & Sí \\
\hline Sativasur & No & $\mathrm{Sd}$ & Sí & Sí \\
\hline Monguí & Sí & Sí & Sí & Sí \\
\hline Pacho & No & No & Sí & No \\
\hline Suesca & No & $\mathrm{Sd}$ & No & No \\
\hline
\end{tabular}




\begin{tabular}{|c|c|c|c|c|}
\hline Municipio & Vocación РОт & PD 2008-2011 & PD 2012-2015 & PD 2016-2019 \\
\hline Chita & No & Sí & Sí & Sí \\
\hline Jericó & No & Sí & Sí & Sí \\
\hline Tuta & No & Sí & Sí & Sí \\
\hline La Uvita & No & Sí & Sí & Sí \\
\hline Cucaita & No & Sí & Sí & Sí \\
\hline Subachoque & No & Sí & No & No \\
\hline Ventaquemada & Sí & No & Sí & Sí \\
\hline Sativanorte & No & No & Sí & Sí \\
\hline Chivatá & $\mathrm{Sd}$ & Sí & Sí & No \\
\hline Beteitiva & No & Sí & Sí & Sí \\
\hline Guatavita & No & No & Sí & Sí \\
\hline Paz del Río & No & No & No & No \\
\hline Motavita & No & No & No & No \\
\hline Santa María & No & $\mathrm{Sd}$ & Sí & Sí \\
\hline Boavita & No & Sí & Sí & Sí \\
\hline Tunja & No & No & No & No \\
\hline Duitama & No & Sí & Sí & Sí \\
\hline Iza & $\mathrm{Si}$ & No & No & No \\
\hline Machetá & No & Sí & No & Sí \\
\hline Úmbita & $\mathrm{Si}$ & No & Sí & $\mathrm{Sd}$ \\
\hline Susacón & No & $\mathrm{Sd}$ & No & No \\
\hline Jerusalén & $\mathrm{Si}$ & Sí & Sí & Sí \\
\hline Pesca & $\mathrm{Si}$ & Sí & Sí & Sí \\
\hline Caparrapí & $\mathrm{Si}$ & Sí & Sí & Sí \\
\hline Turmequé & No & No & No & No \\
\hline Villapinzón & No & No & No & No \\
\hline Nemocón & No & Sí & Sí & Sí \\
\hline $\begin{array}{l}\text { Villa de San Diego de } \\
\text { Ubaté }\end{array}$ & No & No & No & No \\
\hline Boyacá & No & Sí & Sí & Sí \\
\hline Tibaná & No & $\mathrm{Sd}$ & $\mathrm{Sd}$ & No \\
\hline Tota & $\mathrm{Si}$ & $\mathrm{Sd}$ & No & No \\
\hline
\end{tabular}

Fuente: elaboración propia. 
FIGURA 4. COMPARATIVO VOCACIÓN MINERA EN LOS PLANES DE ORDENAMIENTO Y PLANES DE DESARROLLO

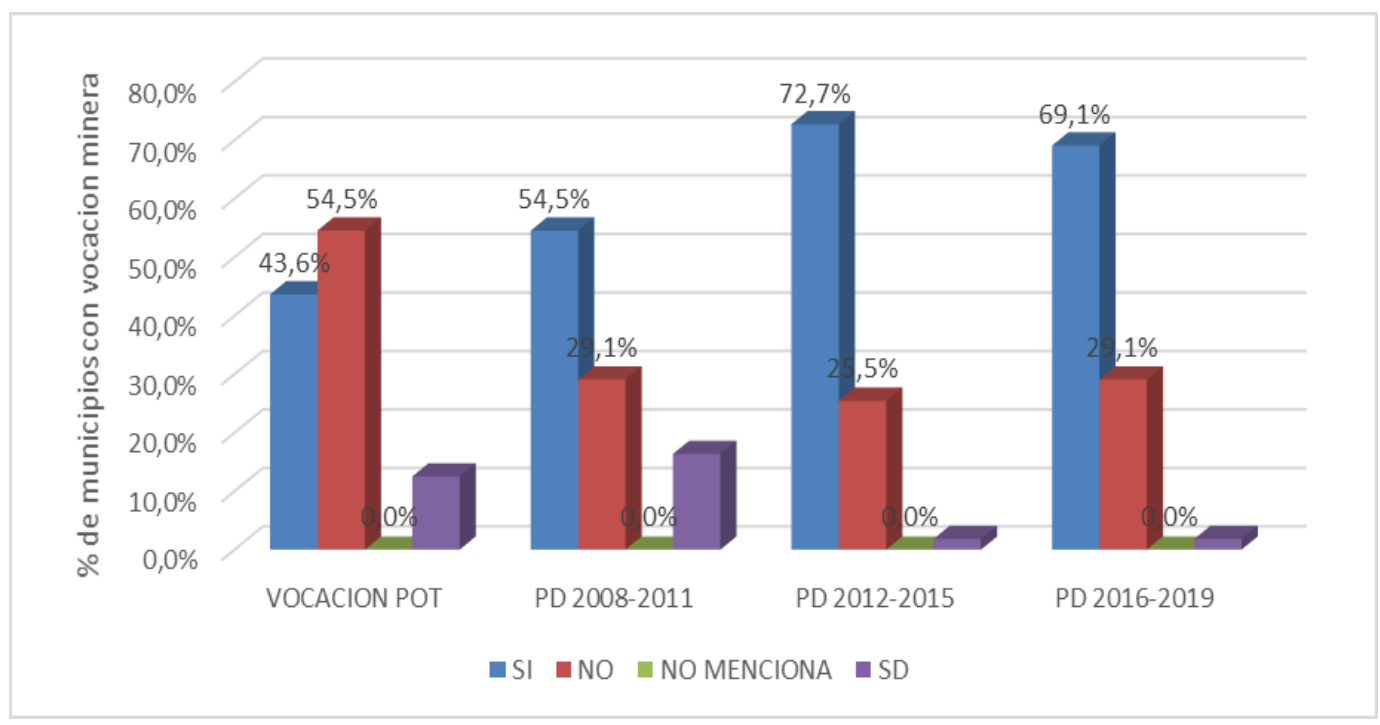

Fuente: elaboración propia.

FIGURA 5. INCLUSIÓN DE REGALÍAS EN EL PLAN DE ORDENAMIENTO Y PLANES DE DESARROLLO

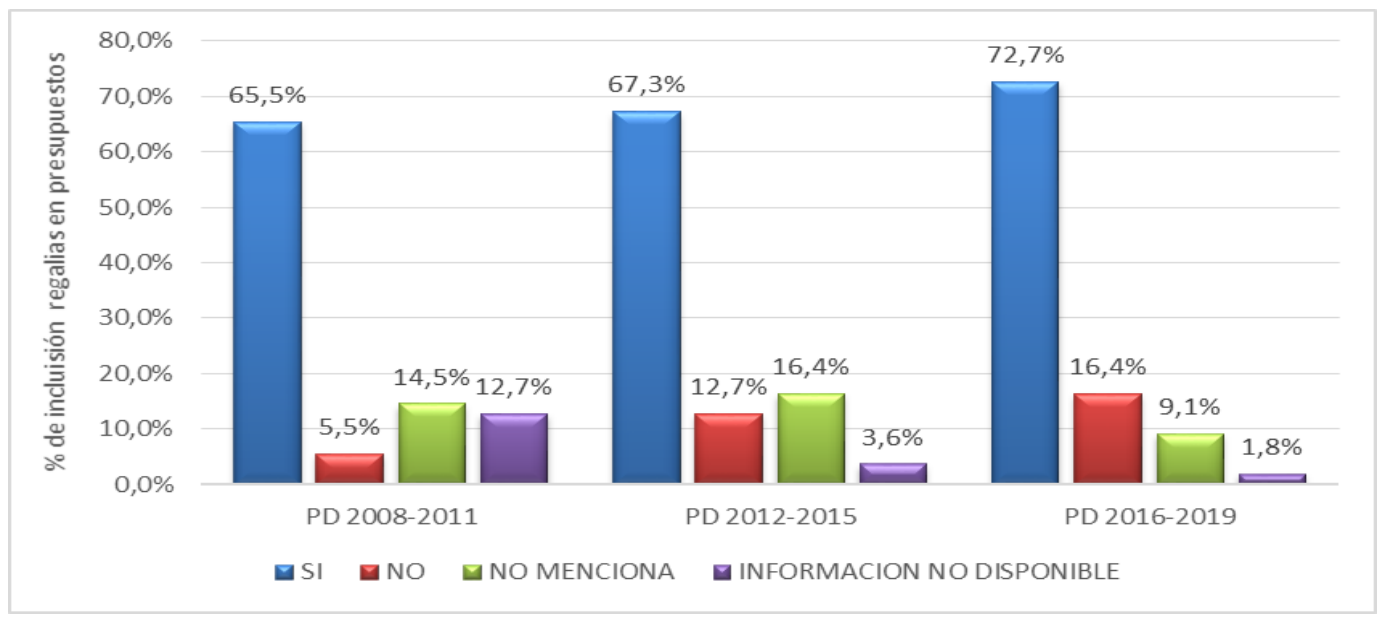

Fuente: elaboración propia. 
TABLA 2. SECTOR DE INVERSIÓN DE LOS RECURSOS DE REGALÍAS DE LOS MUNICIPIOS DE CUNDINAMARCA Y BOYACÁ

\begin{tabular}{|l|c|c|c|c|c|c|}
\hline \multicolumn{1}{|c|}{ Sector } & Municipios & 1ra línea (\%) & Municipios & 2da línea (\%) & Municipios & 3ra línea (\%) \\
\hline Transporte & 18 & 33 & 6 & 11 & 2 & 4 \\
\hline Educación & 9 & 16 & 2 & 4 & 3 & 5 \\
\hline Vivienda, Ciudad y Territorio & 9 & 16 & 5 & 9 & 1 & 2 \\
\hline Agricultura y Desarrollo Rural & 5 & 9 & 4 & 7 & 1 & 2 \\
\hline Deporte y Recreación & 4 & 7 & 9 & 16 & 2 & 4 \\
\hline Inclusión Social y Reconciliación & 3 & 5 & 0 & 0 & 0 & 0 \\
\hline Ambiente y Desarrollo Sostenible & 1 & 2 & 0 & 0 & 0 & 0 \\
\hline Interior & 1 & 2 & 0 & 0 & 1 & 2 \\
\hline Minas y Energía & 1 & 2 & 0 & 0 & 0 & 0 \\
\hline Planeación & 1 & 2 & 0 & 0 & 0 & 0 \\
\hline Trabajo & 0 & 0 & 0 & 0 & 1 & 2 \\
\hline Ciencia, Tecnología e Innovación & 0 & 0 & 0 & 0 & 1 & 2 \\
\hline Comercio, Industria y Turismo & 0 & 0 & 1 & 2 & 0 & 0 \\
\hline Cultura & 0 & 0 & 1 & 2 & 0 & 0 \\
\hline No invirtió & 3 & 5 & 27 & 49 & 43 & 78 \\
\hline Total municipios & 55 & 55 & & 55 & \\
\hline
\end{tabular}

Fuente: elaboración propia.

FIGURA 6. COMPARATIVO NBI MUNICIPIOS PRODUCTORES DEPARTAMENTO DE BOYACÁ

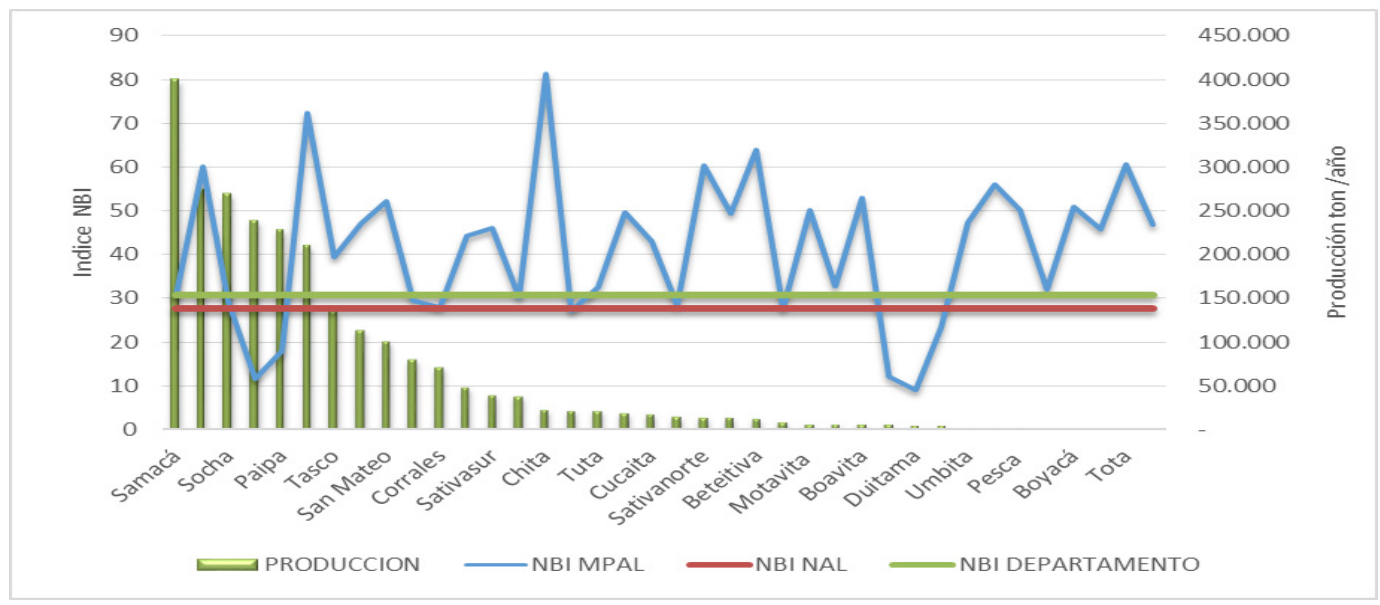

Fuente: elaboración propia. 
FIGURA 7. COMPARATIVO NBI DE CADA MUNICIPIO PRODUCTOR DEL DEPARTAMENTO DE CUNDINAMARCA

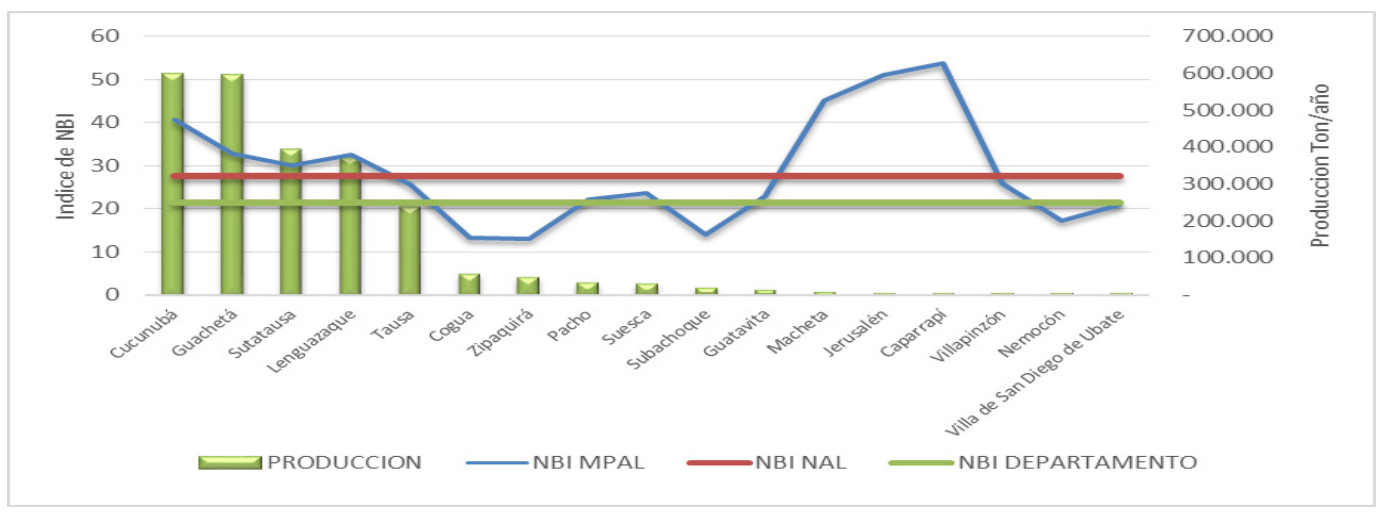

Fuente: elaboración propia.

FIGURA 8. PRODUCCIÓN AÑO POR MUNICIPIO FRENTE A PORCENTAJE DE POBLACIÓN SISBEN. SUBGRUPO 1 - CASO 2

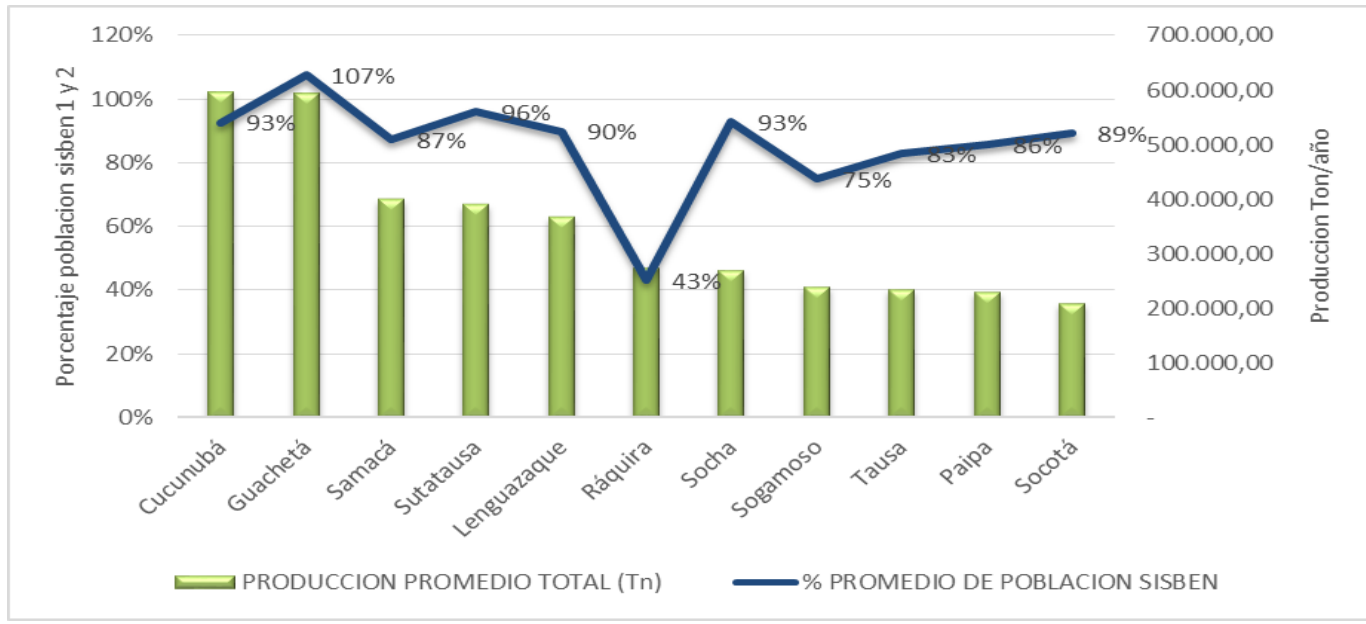

Fuente: elaboración propia. 
FIGURA 9. PRODUCCIÓN AÑO POR MUNICIPIO FRENTE A PORCENTAJE DE POBLACIÓN SISBEN. SUBGRUPO 2 - CASO 2

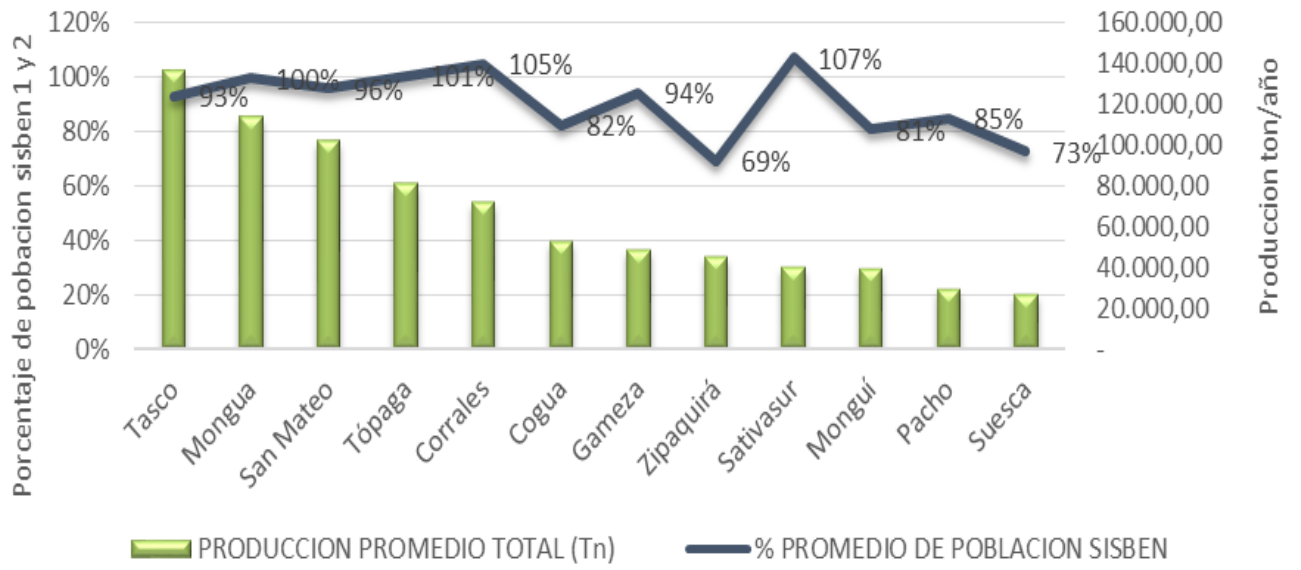

Fuente: elaboración propia.

FIGURA 10. PRODUCCIÓN AÑO POR MUNICIPIO FRENTE A PORCENTAJE DE POBLACIÓN SISBEN. SUBGRUPO 3 - CASO 2

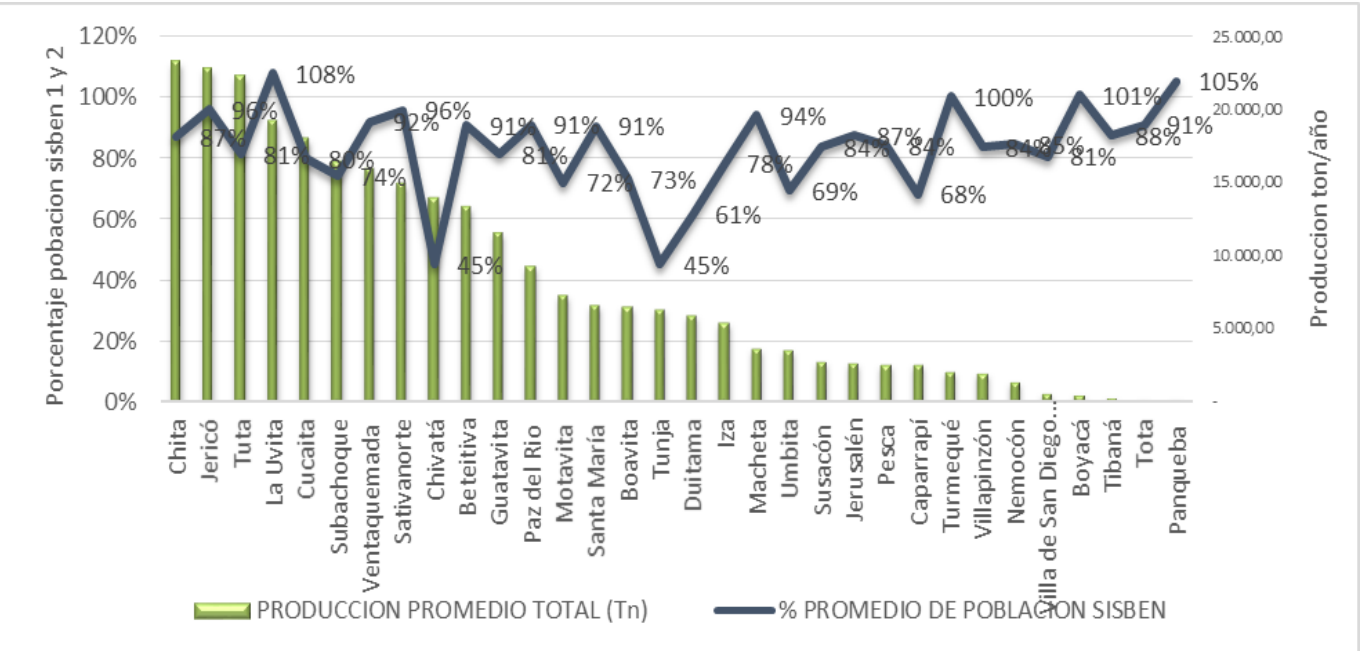

Fuente: elaboración propia. 


\section{ANEXO 3. INFORMACIÓN DE SOPORTE - CASO 3}

FIGURA 1. DEPENDENCIA PROMEDIO DE LAS REGALÍAS EN LOS RECURSOS DE LOS MUNICIPIOS PRODUCTORES DE CARBÓN DE SANTANDER Y NORTE DE SANTANDER FRENTE A PRODUCCIÓN

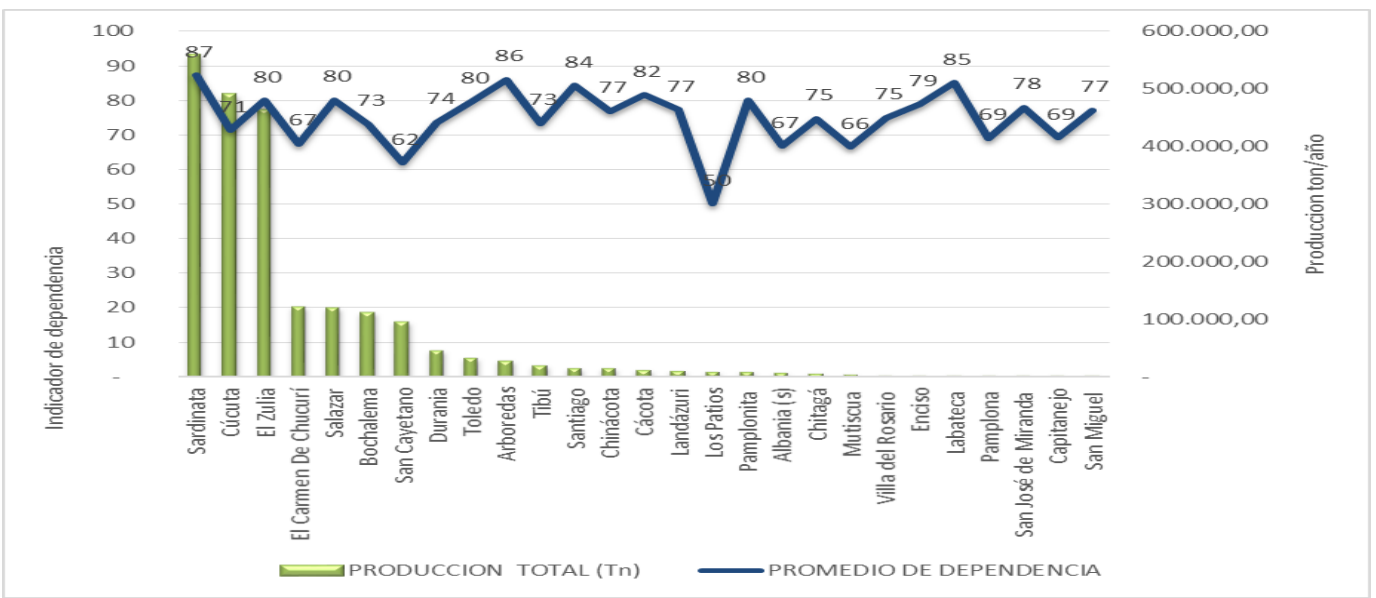

Fuente: elaboración propia.

TABLA 1. COHERENCIA ENTRE EL DESARROLLO DE LA ACTIVIDAD MINERA Y LA VOCACIÓN EN EL PLAN DE ORDENAMIENTO TERRITORIAL Y LA DIMENSIÓN ECONÓMICA DE LOS PLANES DE DESARROLLO

\begin{tabular}{|c|c|c|c|c|}
\hline Municipio & Vocación РОт & PD 2008-2011 & PD 2012-2015 & PD 2016-2019 \\
\hline Sardinata & No & Sd & No & Sí \\
\hline Cúcuta & Sí & Sí & Sí & No \\
\hline El Zulia & Sí & Sí & No & No \\
\hline Salazar & Sí & Sí & Sí & No \\
\hline Bochalema & Sí & $\mathrm{Sd}$ & Sí & Sí \\
\hline San Cayetano & Sí & Sí & No & No \\
\hline Durania & No & Sd & Sd & No \\
\hline Toledo & Sí & No & No & No \\
\hline Arboledas & No & No & No & No \\
\hline Tibú & No & No & No & Sí \\
\hline Santiago & No & Sí & No & No \\
\hline Chinácota & Sí & Sí & Sí & Sí \\
\hline Cácota & No & No & No & Sí \\
\hline Los Patios & No & No & Sí & No \\
\hline Pamplonita & No & Sí & No menciona & No \\
\hline
\end{tabular}




\begin{tabular}{|c|c|c|c|c|}
\hline Municipio & Vocación POT & PD 2008-2011 & PD 2012-2015 & PD 2016-2019 \\
\hline Chitagá & No & No & Sí & Sí \\
\hline Mutiscua & No & Sí & Sí & Sí \\
\hline Villa del Rosario & No & Sí & Sí & No \\
\hline Labateca & No & No & No & No \\
\hline Pamplona & No & Sí & No & No \\
\hline El Carmen de Chucurí & Sí & Sí & No & No \\
\hline Landázuri & No & Sí & Sí & No \\
\hline Albania (s) & No & No & No & No \\
\hline Enciso & Sí & $\mathrm{Sd}$ & Sí & No \\
\hline San José de Miranda & No & $\mathrm{Sd}$ & Sí & No \\
\hline Capitanejo & Sí & No & No & No \\
\hline San Miguel & Sd & No & No & No \\
\hline
\end{tabular}

Sd: $\sin$ dato.

Fuente: elaboración propia.

FIGURA 2. COMPARATIVO DE VOCACIÓN MINERA EN EL POT Y LOS PLANES DE DESARROLLO

$80,0 \%$
$70,0 \%$
$60,0 \%$
$50,0 \%$
$40,0 \%$
$30,0 \%$
$20,0 \%$
$10,0 \%$
$0,0 \%$

$0,0 \%$

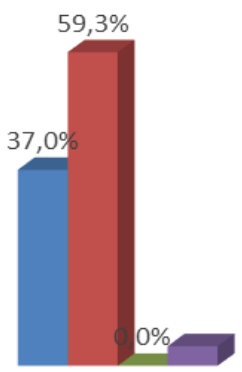

SI

VOCACION POT

aI

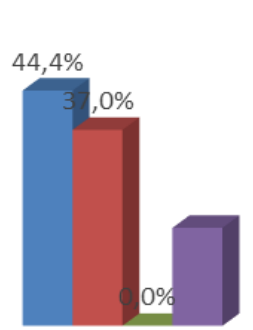

$\mathrm{SI}$

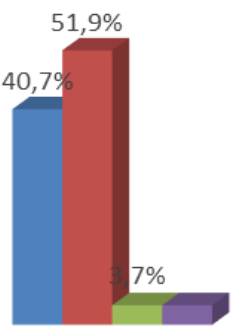

SI

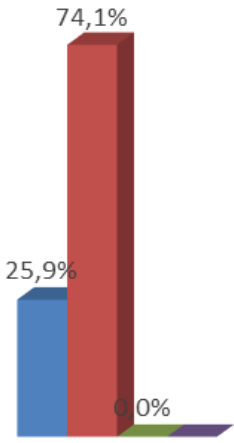

SI
PD 2012-2015

PD 2016-2019

PD 2008-2011

- NO

- NO MENCIONA

- SD 
FIGURA 3. INCLUSIÓN DE REGALÍAS EN LOS PLANES DE DESARROLLO

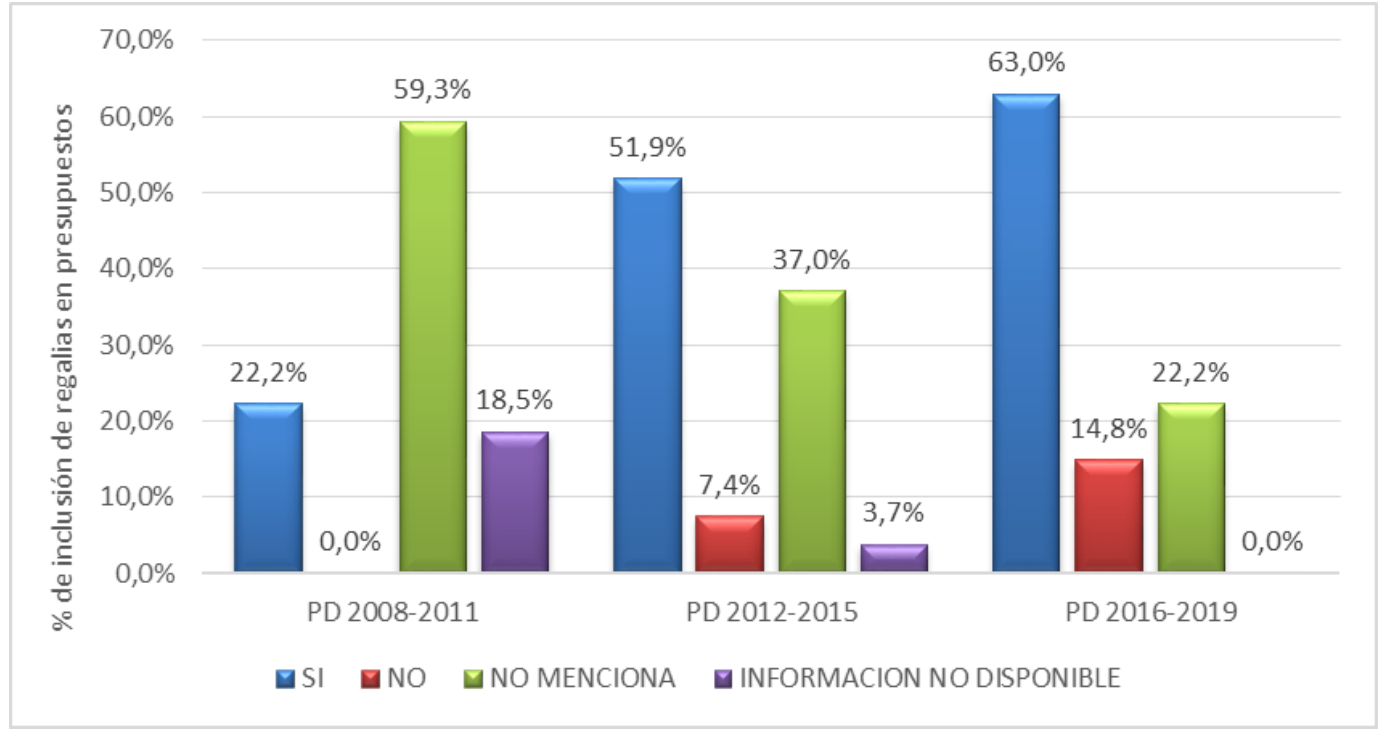

Fuente: elaboración propia.

TABLA 2. SECTOR DE INVERSIÓN DE REGALÍAS POR MUNICIPIO

\begin{tabular}{|c|c|c|c|c|c|c|}
\hline Municipio & Línea 1 & $\%$ & Línea 2 & $\%$ & Línea 3 & $\%$ \\
\hline Albania (S) & Agricultura y Desarrollo Rural & 77 & Transporte & 23 & No invirtió & 0 \\
\hline Arboledas & Transporte & 92 & $\begin{array}{l}\text { Agricultura y Desarrollo } \\
\text { Rural }\end{array}$ & 8 & No invirtió & 0 \\
\hline Bochalema & Vivienda, Ciudad y Territorio & 67 & Transporte & 24 & $\begin{array}{l}\text { Deporte y } \\
\text { Recreación }\end{array}$ & 9 \\
\hline Cácota & Vivienda, Ciudad y Territorio & 84 & $\begin{array}{l}\text { Agricultura y } \\
\text { Desarrollo Rural }\end{array}$ & 16 & No invirtió & 0 \\
\hline Capitanejo & Transporte & 74 & $\begin{array}{l}\text { Vivienda, Ciudad y } \\
\text { Territorio }\end{array}$ & 26 & No invirtió & 0 \\
\hline Chinácota & Transporte & 77 & $\begin{array}{l}\text { Vivienda, Ciudad y } \\
\text { Territorio }\end{array}$ & 22 & $\begin{array}{l}\text { Agricultura y } \\
\text { Desarrollo Rural }\end{array}$ & 1 \\
\hline Chitagá & Agricultura y Desarrollo Rural & 49 & Transporte & 28 & $\begin{array}{l}\text { Inclusión Social y } \\
\text { Reconciliación }\end{array}$ & 24 \\
\hline Cúcuta & Vivienda, Ciudad y Territorio & 100 & No invirtió & 0 & No invirtió & 0 \\
\hline Durania & Transporte & 100 & No invirtió & 0 & No invirtió & 0 \\
\hline $\begin{array}{l}\text { El Carmen De } \\
\text { Chucurí }\end{array}$ & Vivienda, Ciudad y Territorio & 58 & Transporte & 23 & $\begin{array}{l}\text { Deporte y } \\
\text { Recreación }\end{array}$ & 16 \\
\hline El Zulia & Educación & 100 & No invirtió & 0 & No invirtió & 0 \\
\hline
\end{tabular}




\begin{tabular}{|c|c|c|c|c|c|c|}
\hline Municipio & Línea 1 & $\%$ & Línea 2 & $\%$ & Línea 3 & $\%$ \\
\hline Enciso & Cultura & 43 & Transporte & 30 & $\begin{array}{l}\text { Agricultura y } \\
\text { Desarrollo Rural }\end{array}$ & 28 \\
\hline Labateca & Agricultura y Desarrollo Rural & 87 & Transporte & 13 & No invirtió & 0 \\
\hline Landázuri & Transporte & 84 & Cultura & 16 & No invirtió & 0 \\
\hline Los Patios & Transporte & 97 & $\begin{array}{l}\text { Vivienda, Ciudad Y } \\
\text { Territorio }\end{array}$ & 3 & No invirtió & 0 \\
\hline Mutiscua & Transporte & 100 & No invirtió & 0 & No invirtió & 0 \\
\hline Pamplona & Transporte & 100 & No invirtió & 0 & No invirtió & 0 \\
\hline Pamplonita & Transporte & 100 & No invirtió & 0 & No invirtió & 0 \\
\hline Salazar & Transporte & 88 & Educación & 12 & No invirtió & 0 \\
\hline San Cayetano & Vivienda, Ciudad y Territorio & 54 & Deporte y Recreación & 46 & No invirtió & 0 \\
\hline $\begin{array}{l}\text { San José de } \\
\text { Miranda }\end{array}$ & Transporte & 100 & No invirtió & 0 & No invirtió & 0 \\
\hline San Miguel & Transporte & 83 & $\begin{array}{l}\text { Agricultura y Desarrollo } \\
\text { Rural }\end{array}$ & 17 & No invirtió & 0 \\
\hline Santiago & Transporte & 100 & No invirtió & 0 & No invirtió & 0 \\
\hline Sardinata & Vivienda, Ciudad y Territorio & 57 & Transporte & 28 & Educación & 14 \\
\hline Tibú & Transporte & 58 & $\begin{array}{l}\text { Vivienda, Ciudad y } \\
\text { Territorio }\end{array}$ & 26 & Educación & 11 \\
\hline Toledo & Transporte & 95 & Educación & 5 & No invirtió & 0 \\
\hline Villa del Rosario & Educación & 60 & $\begin{array}{l}\text { Vivienda, Ciudad y } \\
\text { Territorio }\end{array}$ & 26 & $\begin{array}{l}\text { Agricultura y } \\
\text { Desarrollo Rural }\end{array}$ & 13 \\
\hline
\end{tabular}

Fuente: elaboración propia.

\section{FIGURA 4. COMPARATIVO ENTRE CALIFICACIÓN DE NBI Y PRODUCCIÓN DE CARBÓN, SANTANDER}

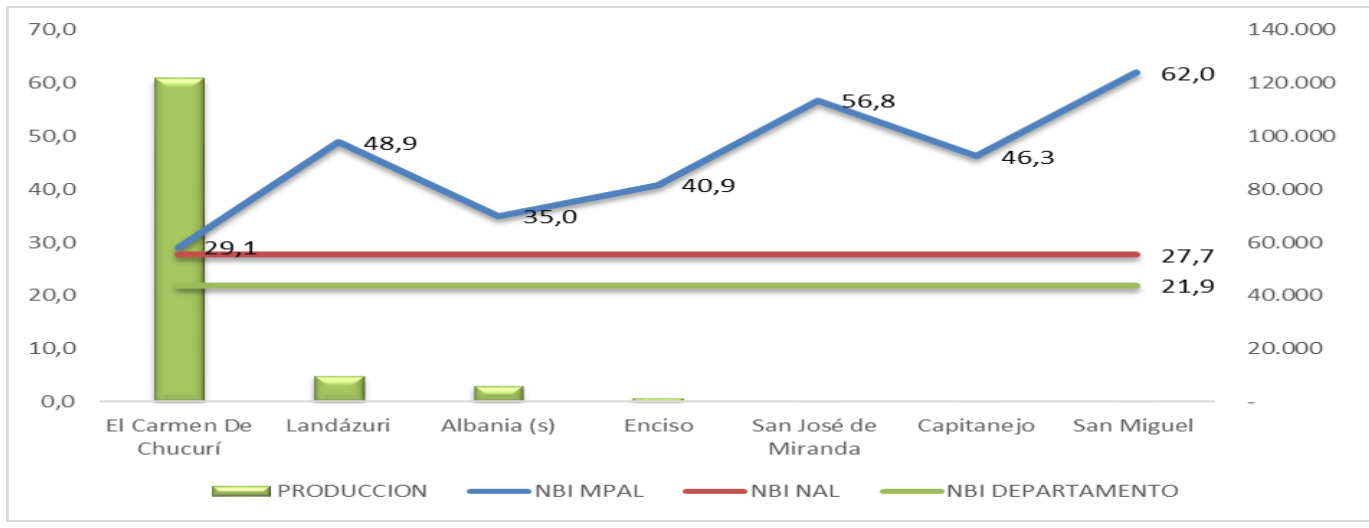

Fuente: elaboración propia. 
FIGURA 5. COMPARATIVO ENTRE CALIFICACIÓN DE NBI Y PRODUCCIÓN DE CARBÓN NORTE DE SANTANDER

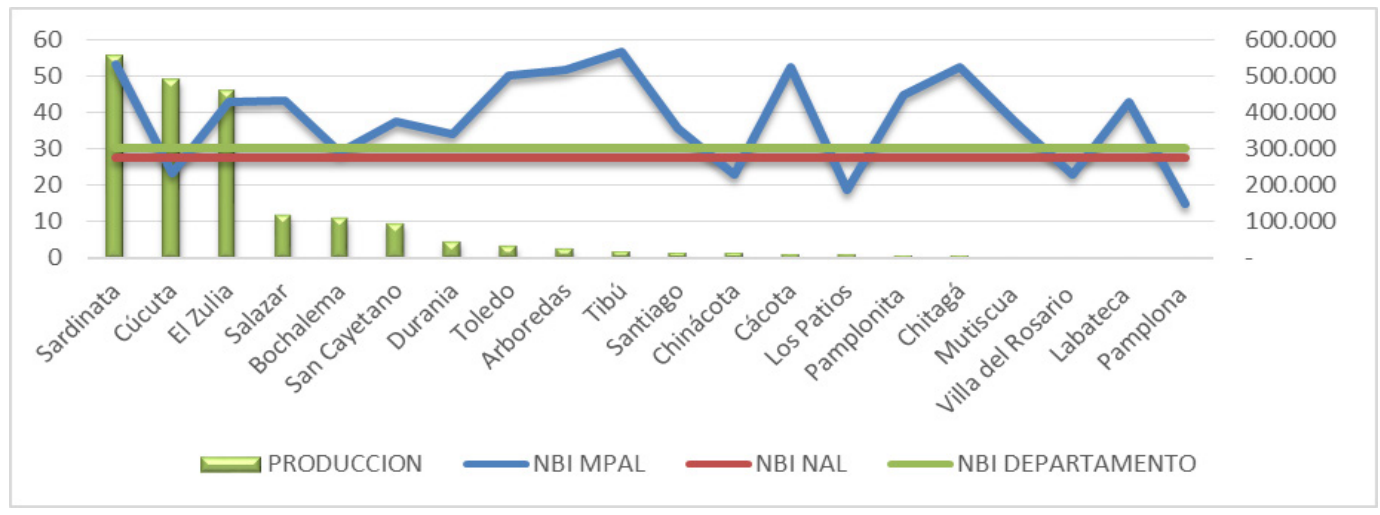

Fuente: elaboración propia.

FIGURA 6. TASA DE CRECIMIENTO DEL SISBEN - POBLACIÓN TOTAL

DE LOS MUNICIPIOS DE NORTE DE SANTANDER Y SANTANDER

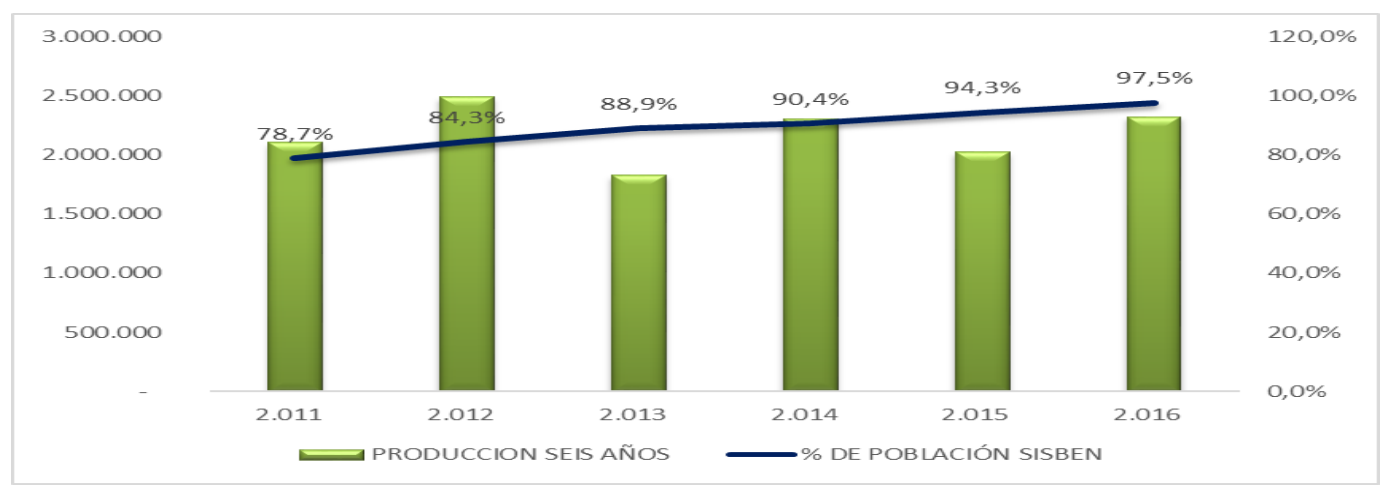

Fuente: elaboración propia. 


\section{ANEXO 4. INFORMACIÓN DE SOPORTE - CASO 4}

FIGURA 1. PRODUCCIÓN FRENTE A DEPENDENCIA PROMEDIO DE LAS REGALÍAS EN LOS RECURSOS DE LOS MUNICIPIOS PRODUCTORES DE CARBÓN

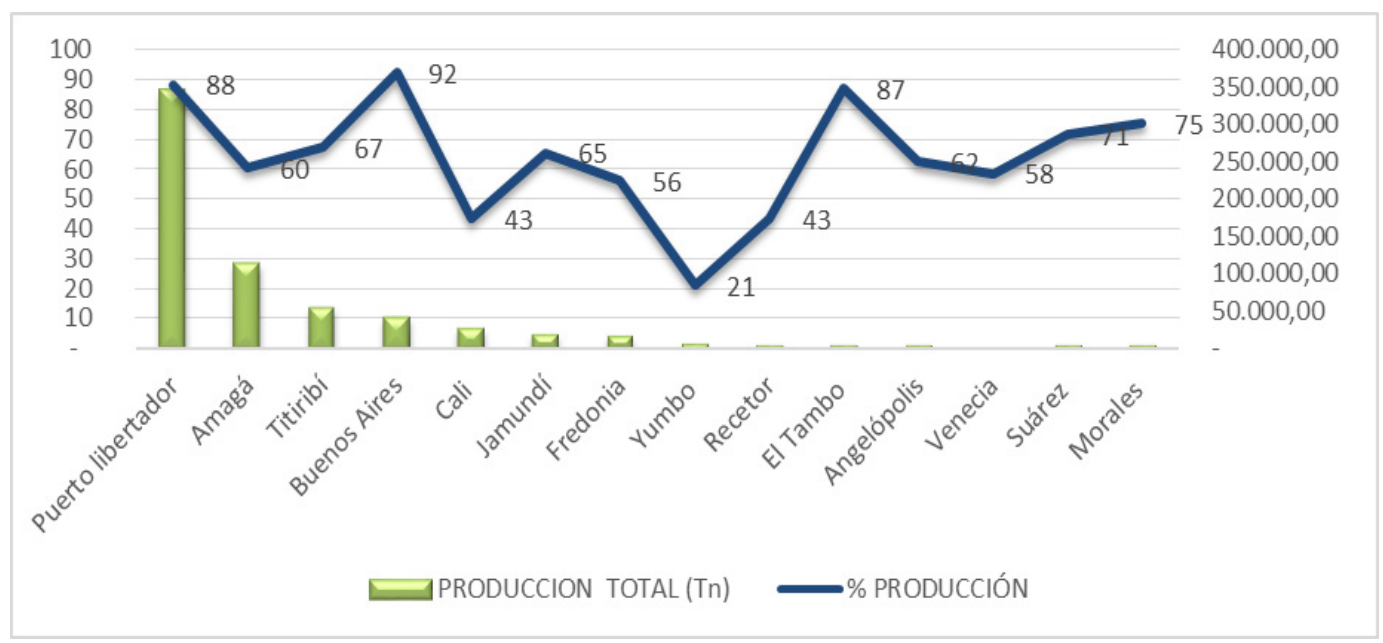

Fuente: elaboración propia.

TABLA 1. COHERENCIA ENTRE EL DESARROLLO DE LA ACTIVIDAD MINERA Y LA VOCACIÓN EN EL PLAN DE ORDENAMIENTO TERRITORIAL Y LA DIMENSIÓN ECONÓMICA DE LOS PLANES DE DESARROLLO

\begin{tabular}{|c|c|c|c|c|c|}
\hline \multirow{2}{*}{ Municipio } & \multirow{2}{*}{ Departamento } & \multirow{2}{*}{ Vocación РОт } & PD & PD & PD \\
\hline & & & 2008-2011 & 2012-2015 & 2016-2019 \\
\hline $\begin{array}{l}\text { Puerto liber- } \\
\text { tador }\end{array}$ & Córdoba & No & Sí & Sí & Sí \\
\hline Amagá & Antioquia & Sí & Sí & No & Sí \\
\hline Titiribí & Antioquia & No & Sí & Sí & No \\
\hline Buenos Aires & Cauca & Sí & Sd & Sí & Sí \\
\hline Cali & Valle del Cauca & Sí & No & No & No \\
\hline Jamundí & Valle del Cauca & No & $\mathrm{Sd}$ & Sí & Sí \\
\hline Fredonia & Antioquia & Sí & Sí & Sí & Sí \\
\hline Yumbo & Valle del Cauca & No & $\mathrm{Sd}$ & Sí & No \\
\hline Recetor & Casanare & Sí & Sí & Sí & Sí \\
\hline El Tambo & Cauca & Sí & $\mathrm{Sd}$ & Sí & Sí \\
\hline Angelópolis & Antioquia & Sí & Sí & Sí & Sí \\
\hline Venecia & Antioquia & Sí & Sí & Sí & Sí \\
\hline Suárez & Cauca & Sí & Sd & Sí & Sí \\
\hline Morales & Cauca & No & Sd & No & No \\
\hline
\end{tabular}


FIGURA 2. COMPARATIVO VOCACIÓN MINERA EN POT Y PLANES DE DESARROLLO - CASO 4

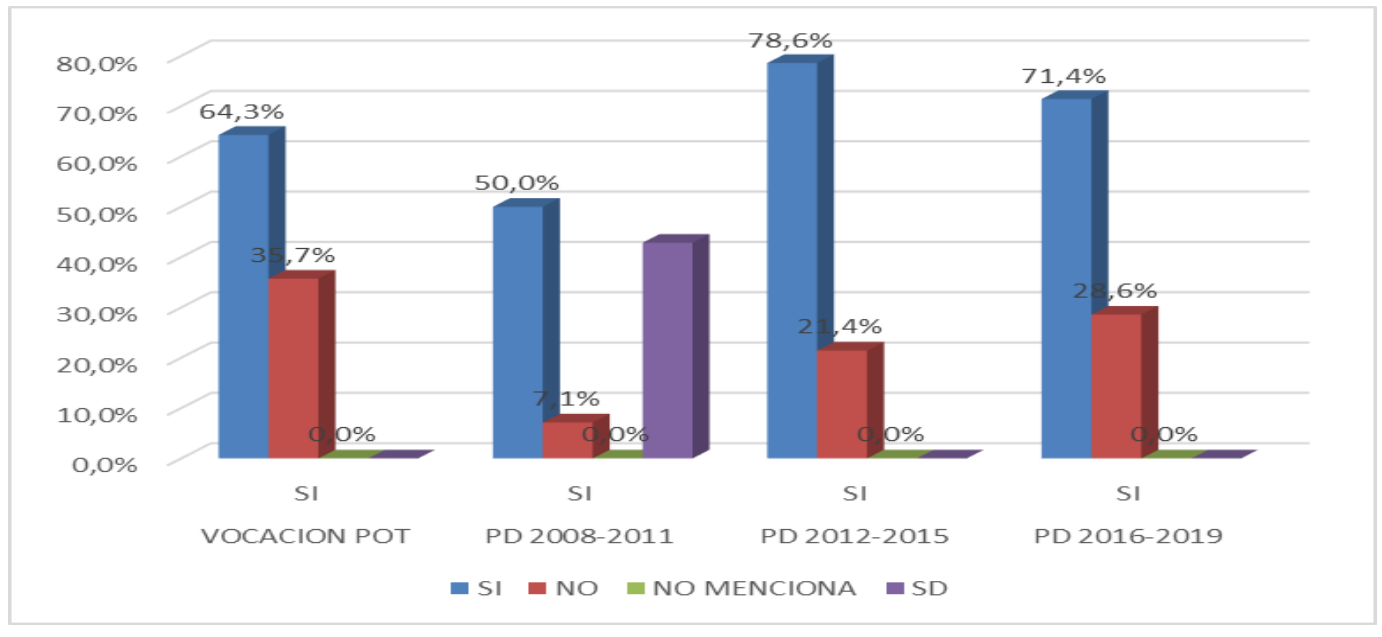

Fuente: elaboración propia.

FIGURA 3. GESTIÓN DE REGALÍAS EN LOS PRESUPUESTOS MUNICIPALES - CASO 4

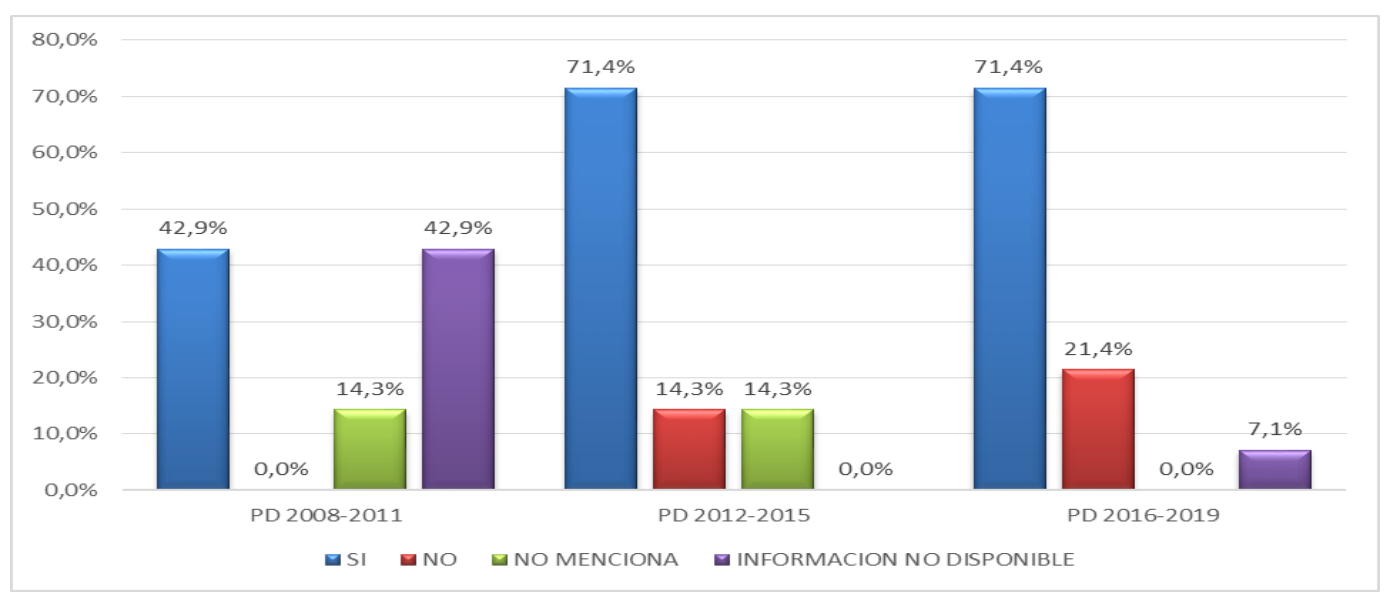

Fuente: elaboración propia. 
TABLA 2. SECTORES DE INVERSIÓN DE LOS RECURSOS DE REGALÍAS - CASO 4

\begin{tabular}{|c|c|c|c|c|c|c|c|}
\hline Municipio & Departamento & Línea 1 & $\%$ & Línea 2 & $\%$ & Línea 3 & $\%$ \\
\hline Amagá & Antioquia & $\begin{array}{l}\text { Deporte y } \\
\text { Recreación }\end{array}$ & 54 & $\begin{array}{l}\text { Agricultura } \\
\text { y Desarrollo } \\
\text { Rural }\end{array}$ & 14 & $\begin{array}{l}\text { Vivienda, } \\
\text { Ciudad y } \\
\text { Territorio }\end{array}$ & 14 \\
\hline Angelópolis & Antioquia & Transporte & 79 & $\begin{array}{l}\text { Deporte y } \\
\text { Recreación }\end{array}$ & 21 & & \\
\hline Buenos Aires & Cauca & $\begin{array}{l}\text { Vivienda, } \\
\text { Ciudad y } \\
\text { Territorio }\end{array}$ & 39 & $\begin{array}{l}\text { Deporte y } \\
\text { Recreación }\end{array}$ & 27 & $\begin{array}{l}\text { Inclusión } \\
\text { Social y } \\
\text { Reconciliación }\end{array}$ & 13 \\
\hline Cali & Valle del Cauca & Cultura & 100 & & & & \\
\hline El Tambo & Cauca & Transporte & 39 & $\begin{array}{l}\text { Agricultura } \\
\text { y Desarrollo } \\
\text { Rural }\end{array}$ & 27 & $\begin{array}{l}\text { Minas y } \\
\text { Energía }\end{array}$ & 16 \\
\hline Fredonia & Antioquia & Cultura & 66 & $\begin{array}{l}\text { Vivienda, } \\
\text { Ciudad y } \\
\text { Territorio }\end{array}$ & 34 & & \\
\hline Jamundí & Valle del Cauca & $\begin{array}{l}\text { Vivienda, } \\
\text { Ciudad y } \\
\text { Territorio }\end{array}$ & 73 & Transporte & 23 & $\begin{array}{l}\text { Inclusión } \\
\text { Social y } \\
\text { Reconciliación }\end{array}$ & 3 \\
\hline Morales & Cauca & Transporte & 96 & $\begin{array}{l}\text { Agricultura } \\
\text { y Desarrollo } \\
\text { Rural }\end{array}$ & 4 & & \\
\hline $\begin{array}{l}\text { Puerto } \\
\text { Libertador }\end{array}$ & Córdoba & Transporte & 90 & $\begin{array}{l}\text { Ambiente y } \\
\text { Desarrollo } \\
\text { Sostenible }\end{array}$ & 4 & $\begin{array}{l}\text { Vivienda, } \\
\text { Ciudad y } \\
\text { Territorio }\end{array}$ & 3 \\
\hline Recetor & Casanare & $\begin{array}{l}\text { Agricultura } \\
\text { Y Desarrollo } \\
\text { Rural }\end{array}$ & 100 & & & & \\
\hline Suárez & Cauca & $\begin{array}{l}\text { Inclusión } \\
\text { Social y } \\
\text { Reconciliación }\end{array}$ & 34 & $\begin{array}{l}\text { Agricultura } \\
\text { y Desarrollo } \\
\text { Rural }\end{array}$ & 27 & $\begin{array}{l}\text { Deporte y } \\
\text { Recreación }\end{array}$ & 26 \\
\hline Titiribí & Antioquia & $\begin{array}{l}\text { Deporte y } \\
\text { Recreación }\end{array}$ & 5 & $\begin{array}{l}\text { Vivienda, } \\
\text { Ciudad y } \\
\text { Territorio }\end{array}$ & 21 & Educación & 20 \\
\hline Venecia & Antioquia & Transporte & 49 & $\begin{array}{l}\text { Vivienda, } \\
\text { Ciudad y } \\
\text { Territorio }\end{array}$ & 28 & Cultura & 20 \\
\hline Yumbo & Valle del Cauca & $\begin{array}{l}\text { Deporte y } \\
\text { Recreación }\end{array}$ & 100 & & & & \\
\hline
\end{tabular}

Fuente: elaboración propia. 
FIGURA 4. ÍNDICE DE PROSPECCIÓN MUNICIPAL, DEPARTAMENTAL Y NACIONAL

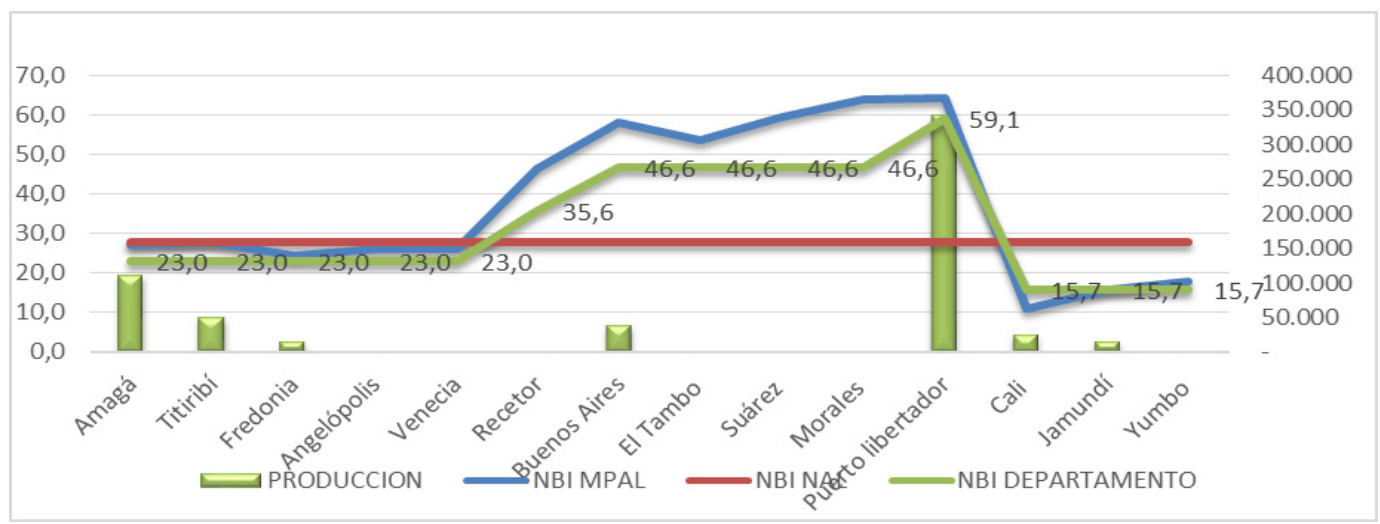

Fuente: elaboración propia. 